\title{
Pseudomonas aeruginosa virulence proteins pseudolysin and protease IV impede cutaneous wound healing
}

\author{
Alevoor Srinivas Bharath Prasad ${ }^{1}$ Padival Shruptha ${ }^{2} \cdot$ Vijendra Prabhu $^{3} \cdot$ Cheruku Srujan $^{2}{ }^{2}$. \\ Usha Yogendra Nayak ${ }^{4}$ - Calicut Kini Rao Anuradha ${ }^{5,6}$ • Lingadakai Ramachandra ${ }^{7}$ Prasad Keerthana ${ }^{8}$. \\ Manjunath B. Joshi ${ }^{1} \cdot$ Thokur Sreepathy Murali $^{2} \cdot$ Kapaettu Satyamoorthy ${ }^{9}$
}

Received: 3 April 2020 / Revised: 15 July 2020 / Accepted: 22 July 2020 / Published online: 15 August 2020

(c) The Author(s) 2020. This article is published with open access

\begin{abstract}
The intricate biological process of cutaneous wound healing is achieved through precise and highly programmed events. Dermal fibroblasts and keratinocytes play a significant role in the process of reepithelialization during wound healing. Pathogenic bacteria such as Pseudomonas aeruginosa ( $P$. aeruginosa) may delay the proliferative phase of wound repair by secreting their proteins leading to delayed or impaired wound healing. We have analyzed three virulent strains of $P$. aeruginosa isolated from the wound environment which also differed in their ability to produce biofilms. Mass spectrometric analysis of differentially expressed secreted proteins by three virulent strains of $P$. aeruginosa revealed peptides from pseudolysin and protease IV expressed from las $B$ and $\operatorname{prpL}$ genes. Pseudolysin and protease IV recombinant proteins were tested for their ability to modulate wound healing in several cell types of wound microenvironment in in vitro and in vivo models. Both pseudolysin and protease IV inhibited migration and survival of fibroblasts, keratinocytes, and endothelial cells. In three dimensional spheroid endothelial models and matrigel assays these proteins impeded sprouting and tube formation. In a mouse model of excision wound, pseudolysin and protease IV treatment showed reduced collagen content, inhibited neovascularization and epithelialization, and delayed wound contraction. Furthermore, pseudolysin and protease IV treatment resulted in a significant increase in plasma IL-6 levels when compared to vehicle control and control, suggesting the induction of a state of prolonged inflammation. Taken together, our data indicate pseudolysin and protease IV secreted from biofilm producing and antibiotic resistant $P$. aeruginosa in wound microenvironment produce both local and systemic effects that is detrimental to the maintenance of tissue homeostasis. Hence, these proteins may serve as potential therapeutic targets toward better clinical management of wounds.
\end{abstract}

Supplementary information The online version of this article (https:// doi.org/10.1038/s41374-020-00478-1) contains supplementary material, which is available to authorized users.

Kapaettu Satyamoorthy

ksatyamoorthy@manipal.edu

1 Department of Ageing Research, Manipal School of Life Sciences (MSLS), Manipal Academy of Higher Education (MAHE), Manipal, India

2 Department of Biotechnology, Manipal School of Life Sciences (MSLS), Manipal Academy of Higher Education (MAHE), Manipal, India

3 Department of Biotechnology, Manipal Institute of Technology, Manipal Academy of Higher Education (MAHE), Manipal, India

4 Department of Pharmaceutics, Manipal College of Pharmaceutical Sciences, Manipal Academy of Higher Education (MAHE), Manipal, India
5 Department of Pathology, Kasturba Medical College (KMC), Manipal Academy of Higher Education (MAHE), Manipal, India

6 Department of Pathology, Yenepoya Medical College, Mangalore, India

7 Department of Surgery, Kasturba Medical College (KMC), Manipal Academy of Higher Education (MAHE), Manipal, India

8 Manipal School of Information Sciences, Manipal Academy of Higher Education (MAHE), Manipal, India

9 Department of Cell \& Molecular Biology, Manipal School of Life Sciences (MSLS), Manipal Academy of Higher Education (MAHE), Manipal, India 


\section{Introduction}

Pseudomonas aeruginosa ( $P$. aeruginosa) is a versatile opportunistic pathogen abundantly present in wound infections [1]. The emerging paradigm of $P$. aeruginosa has evoked much interest in clinical practice throughout the world as it contributes significantly to nosocomial infections [2]. $P$. aeruginosa has the ability to form intractable biofilms and produces a myriad of virulence proteins that confer a significant advantage on its role as a wound pathogen [1]. These virulence factors can degrade the extracellular matrix and alter the cell signaling pathways, thereby facilitating the microorganisms to adhere [3], which subsequently leads to tissue damage and blood vessel invasion. Elastase A, elastase B, protease IV, and alkaline proteases are the major virulence factors produced by $P$. aeruginosa [4]. Elastase B, also called as pseudolysin, is encoded by las $B$ gene that targets the collagen type III from the interstitial extracellular matrix, collagen type IV from the basement membrane, degrades immunoglobulin $\mathrm{A}$ and $\mathrm{G}$, and inhibits fibroblast growth during the host-pathogen interaction $[3,5,6]$. Conversion of plasminogen to plasmin is also inhibited by pseudolysin resulting in the accumulation of the fibrin clots in the wound area [7]. Protease IV, on the other hand, is also known as lysyl endopeptidase encoded by the prpL gene, which is a $26 \mathrm{kDa}$ iron regulated protein belonging to the chymotrypsin family of proteins [8]. Protease IV triggers the host immune defense system by degrading the fibrinogen, plasminogen, immunoglobulin $\mathrm{G}$ and inactivating complement components such as C3 and C1 [9]. However, a clear distinction between these two proteins needs to be biochemically and functionally elucidated. Generally, virulence proteins secreted by pathogens may adversely influence several physiological functions in the host system including wound healing [3].

Wound healing is an intricate and dynamic process encompassing four clearly defined stages such as hemostasis, inflammation, repair, and remodeling. These four stages are intimately interconnected through coordinated cell signaling effects of stromal cells to initiate the local release of various cytokines, chemokines, growth factors, and matrix proteins. Disruption of any of these stages may delay the wound-healing process [10] and these are influenced intrinsically by several local and systemic factors which may play a significant role in delaying the woundhealing process [11]. However, extrinsic factors such as infections are of a major concern which can severely impact the orderly orchestrated plasticity of wound healing. The impact of the biological molecules arising from the pathogen on the host is poorly understood. Our efforts in search of host effects of virulence proteins from $P$. aeruginosa in vitro and in vivo models led us to identify pseudolysin and protease IV as key virulence proteins that determine the delayed wound-healing process.

\section{Materials and methods}

\section{Cell culture}

Human foreskin fibroblasts were isolated after obtaining the ethical clearance from the institutional ethics committee, Kasturba Medical College, Manipal Academy of Higher Education, Manipal, India. Written informed consent from the donors were obtained. Isolation of fibroblasts was performed using skin epidermis (human dermal fibroblasts (HDF)), characterized and cells were grown in Dulbecco's Modified Eagle Medium (DMEM) with $10 \%$ fetal bovine serum (FBS) (Himedia, Mumbai, India). Human keratinocytes (HaCaT) cell lines obtained from ATCC and cells were grown in DMEM supplemented with 10\% FBS. Human endothelial cells (human umbilical vein endothelial cells-HUVECs) were cultured using endothelial cell growth medium (ECGM) containing growth supplements (Promo cell GMBH, Germany) as described earlier [12].

\section{Microorganisms, vectors, media}

$P$. aeruginosa strains used in the study were isolated from the wounds of diabetic foot ulcer individuals [1]. Samples were collected from consenting individuals after obtaining the Institutional Ethics Committee approval of Kasturba Medical College, MAHE, Manipal. P. aeruginosa was grown in tryptic soy broth (TSB) with $1 \%$ glucose at $37^{\circ} \mathrm{C}$ under aerobic conditions. E. coli DH $5 \alpha$ (Novogen, Germany) was used for cloning experiments. Vector pET 28 a (+) (Novogen, Germany) and E. coli BL21 (DE3) (Novogen, Germany) strain was used for the protein expression. 2X YT medium containing Kanamycin was used to grow the bacteria with the recombinant construct at $37^{\circ} \mathrm{C}$. The reference strain used in the study was $P$. aeruginosa ATCC 27853.

\section{Analysis of biofilm formation}

Biofilm formation of $P$. aeruginosa isolates collected from 50 human subjects was assessed by tissue culture plate method [13]. Overnight grown cultures of $P$. aeruginosa were diluted in TSB to an optical density of 0.1 at $600 \mathrm{~nm}$. Cultures were then transferred to the individual wells of a sterile polystyrene flat bottom 96-well culture plates. The plates were incubated for $24 \mathrm{~h}$ at $37^{\circ} \mathrm{C}$ in a static incubator and post incubation period; the wells were washed with phosphate buffered saline (PBS). $0.1 \%$ crystal violet was used to stain the biofilms formed and solubilized using 30\% glacial acetic acid. The amount of biofilm formed was quantified using plate reader (Varioskan $^{\mathrm{TM}}$ Thermo Scientific) by measuring the absorbance at $570 \mathrm{~nm}[1]$. 


\section{Confocal laser scanning microscopy (CLSM)}

Biofilms formed by $P$. aeruginosa strains were visualized by confocal microscopy as described earlier [14]. Briefly, biofilms were allowed to form on coverslips, which were placed on a 6-well plate under culture conditions as described above. Coverslips with biofilms were fixed using 4\% paraformaldehyde, stained using BacLight bacterial live/dead (SYT09-PI) staining (Thermo Fisher Scientific ${ }^{\mathrm{TM}}$, USA) and mounted on a glass slide. Using the excitation/ emission maxima of $480 / 500 \mathrm{~nm}$ for SYTO9 and 490/635 $\mathrm{nm}$ for PI, mounted slides were observed using confocal microscope (CLSM, Leica, Germany).

\section{Antibiotic sensitivity test}

The antibiotic susceptibility of $P$. aeruginosa isolates was assessed by the Kirby-Bauer disc diffusion method on Muller Hinton agar plate. $P$. aeruginosa strains were inoculated in TSB medium and incubated overnight at $37^{\circ} \mathrm{C}$ for $18 \mathrm{~h}$. The cultures were then diluted with TSB to $0.5 \mathrm{McFarland}$ standard and lawn culture of the suspension was made on Muller Hinton agar plates. The discs of sets of ten antibiotics with various concentrations (HiMedia, India) as indicated (Table S1) were placed and incubated for $18-24 \mathrm{~h}$ at $37^{\circ} \mathrm{C}$. The interpretation of the results was done as recommended by the Clinical and Laboratory Standards Institute guidelines.

\section{Preparation of $\boldsymbol{P}$. aeruginosa culture conditioned medium}

The biofilm-forming strain of $P$. aeruginosa was grown in TSB with $1 \%$ glucose at $37^{\circ} \mathrm{C}$ under aerobic conditions for 16-18 h. TSB medium alone was used as blank and incubated as mentioned above. The cultures were then centrifuged and $0.2 \mu \mathrm{m}$ membrane filter (Millipore, USA) was used to filter the supernatant [15] lyophilized and the concentration of protein was estimated by Lowry method.

\section{Cytotoxicity assay}

$\mathrm{HDF}$ and $\mathrm{HaCaT}$ cells were seeded at a density of $0.5 \times 10^{4}$ and $1 \times 10^{4}$ cells $/ \mathrm{mL}$, respectively, in a 96-well cell tissue culture plates with DMEM (GIBCO-Invitrogen) supplemented with $10 \%$ FBS and allowed the cells to attach. The cells were treated with different concentrations of proteins diluted using DMEM medium with FBS for $48 \mathrm{~h}$. MTT (3[-dimethylthiazol-2-yl]-2,5-diphenyl-tetrazolium bromide) was then added and formazan crystals formed were then dissolved and absorbance was measured at $570 \mathrm{~nm}$ using a plate reader (Varioskan ${ }^{\mathrm{TM}}$ Thermo Scientific, USA).

\section{Cell migration assay}

$\mathrm{HDF}$ and $\mathrm{HaCaT}$ cells were seeded in 12-well cell culture plates and grown in DMEM containing 10\% FBS. Cells were grown to $80 \%$ confluency and prior to the experiment, cells were serum starved overnight in the serum-free culture medium. A wound scratch was made on monolayer cells with the help of a sterile $200 \mu \mathrm{L}$ pipette tip [16]. Cells were then treated as indicated in figure legends and cell migration ability for different cell types was monitored. The area covered after cell migration was analyzed using the ImageJ software (Wayne Rasband, USA).

\section{Generation of LasB and prpL plasmid constructs}

DNA fragments coding for lasB gene, and $\operatorname{prpL}$ gene (900 bp, $33 \mathrm{kDa}$, mature pseudolysin and $733 \mathrm{bp}, 26 \mathrm{kDa}$, mature protease IV) were amplified from the genomic DNA of $P$. aeruginosa. The primers used were 5'-ATTGGATCC GAGGCGGGCGGCCCCGGCGG-3' ${ }^{\prime}$ and $5^{\prime}$-ATACTCGA GGAGCTTACAACGCGCTCG- $3^{\prime}$ to amplify $L a s B$ gene, while primers $5^{\prime}$-TATGGATCCGCCGGCTACCGCGACG G- $3^{\prime}$ and $5^{\prime}$-GCCTCGAGGGGCGCGAAGTAGCGGGAG A- $3^{\prime}$ were used to amplify $p r p L$ gene. The purified PCR products and pET 28 a (+) vectors were digested separately using BamHI and XhoI restriction endonucleases. The digested plasmid and PCR products were ligated with T4 DNA ligase and transformed into DH $5 \alpha$. Recombinant clones were further verified by Sanger sequencing (Applied Biosystems 3130, USA) and transformed into $E$. coli BL21 (DE3) cells to produce recombinant proteins.

\section{Expression and purification of recombinant proteins}

Cells containing the plasmid constructs were grown in $2 \mathrm{X}$ YT medium at $37^{\circ} \mathrm{C}$ with kanamycin $(150 \mu \mathrm{g} / \mathrm{mL})$, to an absorbance of $0.6-0.9$ at $600 \mathrm{~nm}$. The protein expressions were induced by adding $0.1 \mathrm{mM}$ isopropyl- $\beta$-D-thiogalactopyranoside (IPTG). After $4 \mathrm{~h}$, cells were lysed using lysis buffer $(500 \mathrm{mM} \mathrm{NaCl}, 50 \mathrm{mM}$ TRIS, $10 \mathrm{mM}$ Imidazole, 10\% Glycerol) and disrupted by high-pressure homogenization using APV 1000 homogenizer (SPX, USA) at 800 bar. After centrifugation, the cell-free supernatants were passed through Ni-NTA column and pseudolysin or protease IV was eluted from the Ni-NTA column using elution buffer with varying concentrations of imidazole. The eluted pseudolysin and protease IV were dialyzed against PBS and concentrated using Amicon Ultra-10 kDa concentrator (Merck-Millipore, Germany) at $4000 \mathrm{~g}$ at $4{ }^{\circ} \mathrm{C}$ for $20 \mathrm{~min}$. The purity of recombinant pseudolysin and protease IV was assessed using 12\% SDS-PAGE. 


\section{Identification of secretory proteins by LC-MS}

Lyophilized condition medium of $P$. aeruginosa was reconstituted, separated on $12 \%$ polyacrylamide gel electrophoresis (SDS-PAGE) and stained with Coomassie blue. The protein bands were excised from the gel and processed as described earlier [17]. Furthermore, tryptic products of proteins were subjected to in Mass spectrometer (6520 accurate-mass Q-TOF, Agilent Technologies, USA) coupled to liquid chromatography. Peptides were resolved in a reverse phase $\mathrm{C} 18$ column with $5 \mu \mathrm{m}$ diameter and $4.6 \times$ $150 \mathrm{~mm}$ length (Agilent Technologies, Santa Clara) and eluted in a gradient of 3-70\% acetonitrile with a flow rate of $0.4 \mu \mathrm{L}$ for $45 \mathrm{~min}$. MS/MS spectra were processed using Qualitative Mass Hunter (Agilent Technologies, USA), exported as MASCOT (.mgf), and searched against the Swiss-Prot database using Mascot version 2.3 (Matrix Science Limited, UK).

\section{Analysis of angiogenic activities in HUVEC cells}

\section{Tube formation assay}

Tube forming assay was performed using HUVECs as described earlier [12]. $60 \mu \mathrm{l}$ of matrigel was coated on 96-well plate and incubated for $1 \mathrm{~h}$ at $37^{\circ} \mathrm{C}$. Cells at a concentration of $2 \times 10^{4}$ cells/well were seeded on the matrigel and treated with pseudolysin and protease IV at different concentrations as indicated and bFGF $(10 \mathrm{ng} / \mathrm{mL})$ as positive control. Tube formation was assessed after $6 \mathrm{~h}$ of incubation at $37^{\circ} \mathrm{C}$. Images were captured using a microscope (Zeiss Axiovision, Germany) and quantified using ImageJ software.

\section{Sprout formation assay}

Three dimensional cultures of HUVECs were prepared in $20 \%$ methyl cellulose containing ECGM. Cells were suspended as hanging drops on Petri plates and were incubated at $37^{\circ} \mathrm{C}$. The spheroids formed were placed on the collagen matrix and treated with pseudolysin and protease IV with different concentrations as indicated in the figure legend and bFGF $(10 \mathrm{ng} / \mathrm{mL})$ as positive control. These spheroids were incubated for further $24 \mathrm{~h}$. The number and the length of the sprouts formed were captured using microscope (Zeiss Axiovision, Germany) and were measured using ImageJ software.

\section{In vivo wound induction in mice}

In all, 6-8-week-old Swiss albino healthy male mice (25-30 g) were obtained from an inbred colony maintained at the central animal facility at MAHE under the controlled conditions of temperature $\left(23 \pm 2{ }^{\circ} \mathrm{C}\right)$, humidity $(50 \pm 5 \%)$, and light cycle ( $14 \mathrm{~h}$ of light and $10 \mathrm{~h}$ dark). Study was approved by the Institutional Animal Ethics Committee (IAEC/KMC/101/2017). The dorsal part of the animal skin was shaved and anesthetized by intraperitoneal injection with the cocktail of $65 \mathrm{mg} / \mathrm{kg}$ Ketamine (Aneket, Neon Laboratories, India) and $8 \mathrm{mg} / \mathrm{kg}$ Diazepam (Calmpose, Ranbaxy Laboratories, India). Excisional wounds $\left(1.5 \mathrm{~cm}^{2}\right)$ were created on animals as described earlier [18]. Each animal was maintained in a separate polypropylene cage.

\section{Gel formulation and topical application of proteins}

One percent Carbopol 934 (500 kDa), polymer gel was used as the vehicle control. Triethanolamine was used to neutralize the $\mathrm{pH}$ of the gel. Protein loaded 1\% carbopol 934 gel formulation was prepared by taking $1 \mathrm{mg} / \mathrm{mL}$ of proteins. Post formulation, the stability of the protein was measured at different time points and protein concentrations were estimated by the Lowry method. Homogeneity, texture, and transparency of the formulation were tested after the polymerization [19]. The $\mathrm{pH}$ of the gel was measured using a $\mathrm{pH}$ meter (Eutech, Instruments, Thermo Scientific, USA).

Mice $(n=96)$ were stratified into four groups; each group containing 24 animals. Group 1: control; Group 2: vehicle control (treated only with $50 \mu \mathrm{g}$ of carbopol 934); Group 3: pseudolysin treatment $(50 \mu \mathrm{g})$; and Group 4: protease IV treatment $(50 \mu \mathrm{g})$. For both vehicle control and treatment groups (Groups 3 and 4), topical application of the formulation was applied twice daily. Animals assigned to the control group were devoid of any treatment throughout the experiment. Mice in each group were further used for performing the following analysis: kinetics of wound healing $(n=6 /$ group); histological analysis ( $n=9 /$ group); biochemical parameters ( $n=9 /$ group $)$.

\section{Assessment of wound healing and contraction}

Wound healing was monitored in 24 animals (six from each group) by taking the photographic images of the wounds on every alternate day using Nikon Coolpix P7700 camera at a fixed height and measured using ImageJ software until the wound closure. The wound area on day 1 was considered as $100 \%$ and the healing time was noted over a period; mean wound healing time for animals for each group was measured, documented, and represented.

\section{Histological studies}

Histological analysis was performed on the granulation tissue/ skin samples taken from three animals of each experimental group on the 6th, 12th, and 18th day post wounding following euthanization ( $n=9$ /group). The granulation tissues were initially fixed in $10 \%$ formalin. Tissues were then processed and embedded in paraffin wax for further histological 
evaluation. From each tissue block, 5- $\mu \mathrm{m}$ thickness tissue sections were taken using a microtome (Leica RM2125RT, Germany), stained with haematoxylin-eosin (H\&E) and Masson trichrome (MT). Qualitative assessment of inflammatory state, epithelialization, neovascularization, and collagen synthesis was performed by a pathologist in a blinded fashion. Quantitative assessment of collagen deposition was performed on MT stained tissue sections by digitally analyzing the images using the TissueQuant software (https://ma nipal.edu/sois/research/TQ_Tool.html).

\section{Immunohistochemistry}

Paraffin-embedded sections $(5 \mu \mathrm{m})$ were deparaffinized and rehydrated. Sections were then subjected to antigen retrieval and stained according to the manufacturer's manual (Cell Signaling Technologies, USA). Assessment of cell proliferation was done by staining tissue sections with rabbit anti-Ki67 (1:400) and the angiogenic process was assessed by staining the tissue sections with rabbit anti-CD31 primary antibodies (1:200 diluted) (Cell Signaling Technologies, USA) separately for overnight at $4{ }^{\circ} \mathrm{C}$. These tissue sections were then stained with biotinylated secondary antibodies at room temperature for $1 \mathrm{~h}$ and incubated with avidin-HRP solution. The tissue sections were then developed with 3, 3'-diaminobenzidine solution and counterstained with haematoxylin. Tissue sections were then observed and scored microscopically (Olympus BX51, Japan). The proliferation index and quantification of neo vessel formation were calculated on Ki67 and CD31 stained cells by digitally analyzing the images using the TissueQuant software.

\section{Quantification of IL-6, lipid peroxidation, and collagen}

Blood and granulation tissue samples from three animals of each experimental group were collected on 6th, 12th, and 18th day post wounding following euthanization ( $n=9 /$ group). Blood samples were then centrifuged at $2000 \mathrm{~g}$ for $10 \mathrm{~min}$ and plasma samples were stored in $-80{ }^{\circ} \mathrm{C}$ for further analysis. IL-6 levels were estimated using ELISA Kit (R\&D systems, USA) according to the manufacturer's manual. Granulation tissues were snap-frozen and stored at $-80^{\circ} \mathrm{C}$ for the hydroxyproline and lipid peroxidation estimation. For lipid peroxidation assay, tissue samples were homogenized using homogenization buffer $(0.1 \%$ SDS, $1 \%$ Tween-20, 5 mM EDTA, 1X PBS) containing protease inhibitor (Roche Diagnostics, Switzerland). Tissue homogenate was also prepared in $1 \mathrm{mM}$ ascorbic acid and lipid peroxidation in tissue homogenates was measured as thiobarbituric acid reactive substances (TBARS) using UV-visible spectrophotometer, the wavelength of $532 \mathrm{~nm}$. Estimation of hydroxyproline was performed from the tissue homogenate as described earlier [20]. The absorbance of the sample was measured using UV-visible spectrophotometer at $550 \mathrm{~nm}$ (Varioskan ${ }^{\mathrm{TM}}$, Thermo Scientific, USA).

\section{Statistical analysis}

The data were presented as mean \pm SD or otherwise indicated. Statistical analysis was done using one-way analysis of variance that was used for Bonferroni's multiple comparisons test. Statistical significances were considered at $p$ value: $* p<0.05, * * p<0.01$, and $* * * p<0.001$. Statistical analysis was performed using GraphPad Prism 8.0 (San Diego, USA).

\section{Results}

\section{Pseudomonas strains from wound microenvironment differ in their ability to produce biofilms and resistance against antibiotics}

Pseudomonas strains isolated from 50 consecutive individuals diagnosed with diabetic foot ulcer were initially stratified based on their ability to produce biofilms. Biofilm-forming strains were identified based on the absorbance value after crystal violet staining and confocal microscopy. The strains were categorized as high (OD>0.24), moderate (OD $0.12-0.24)$, and low $(\mathrm{OD}<0.12)$ biofilm producers. Among 50 strains of $P$. aeruginosa tested, 15 were considered as low, 9 as moderate, and 26 as high biofilm-forming organisms, respectively (Fig. S1). Based on the antimicrobial resistance profile (Fig. S2) for 10 different antibiotics, the 50 strains were classified into three groups as Group 1 strains which were resistant to 3 or lesser antibiotics, Group 2 strains were resistant to 4-7 antibiotics, and Group 3 strains which showed resistant to more than 7 antibiotics. We found that 27 of the strains belonged to Group 1, 10 strains to Group 2, and 13 strains to Group 3. For further analysis, one strain from each of the above three groups was chosen. Strain PA950 was chosen from Group 3 as it showed the highest biofilmforming ability, PA957 was chosen from Group 2 with moderate biofilm-forming ability, while PA958 from Group 1 showed lesser biofilm-forming ability (Fig. 1a).

\section{Analysis of biofilm formation by confocal laser microscopy}

Representative images of biofilm formed by various strains of P. aeruginosa are shown in Fig. 1b. BacLight bacterial live/ dead (SYT09-PI) staining was used to describe the architecture of biofilm. Thick and dense layers of biofilm were observed in high biofilm-forming $P$. aeruginosa strain, whereas a thin and sparse layer of biofilm was observed in medium and low biofilm-forming strains of $P$. aeruginosa. 


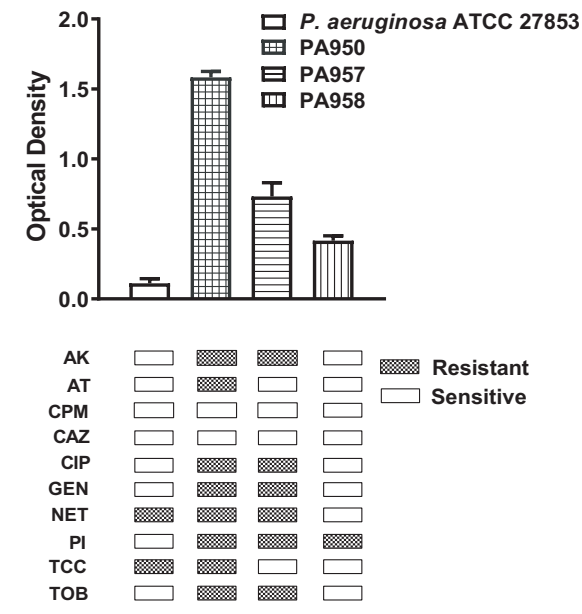

A

Fig. $1 P$. aeruginosa strains show varied ability to produce biofilms and resistance against antibiotics. Biofilm formation and antibiotic resistance pattern of $P$. aeruginosa ATCC 27853 strain, high, moderate, and low biofilm-forming strains of $P$. aeruginosa. a Biofilm production of $P$. aeruginosa strains and antibiotic resistance

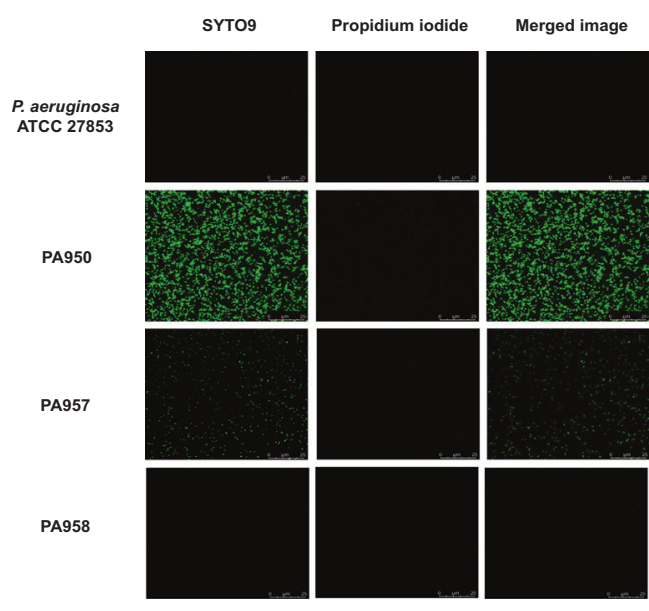

B

pattern of the corresponding strains. b Confocal microscope images of biofilm formation by ATCC 27853 strain, high, moderate, and low biofilm-forming strains of $P$. aeruginosa after $24 \mathrm{~h}(\times 100$ magnification). Scale bars correspond to $25 \mu \mathrm{m}$.

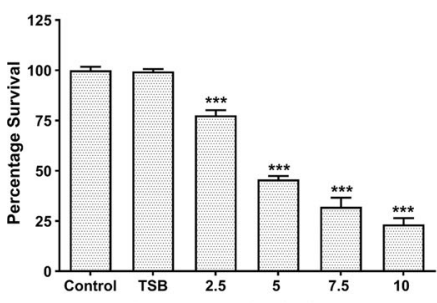

A

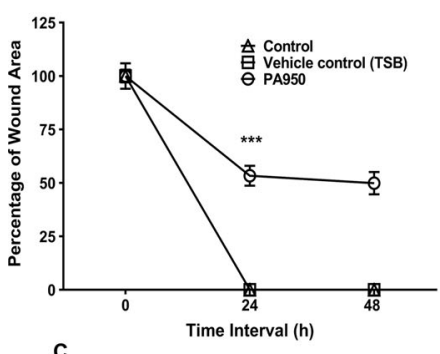

C

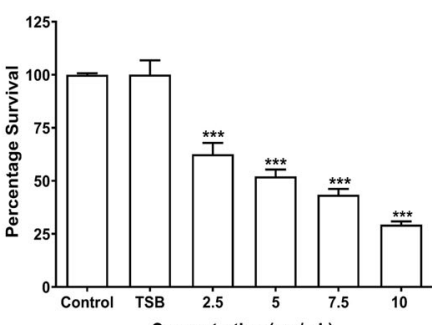

B

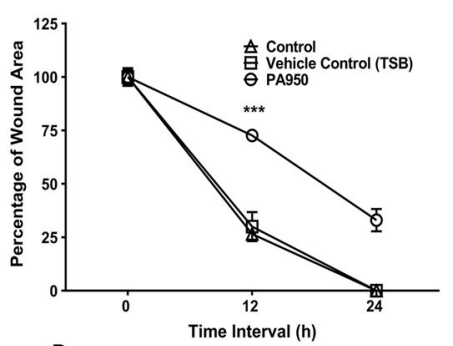

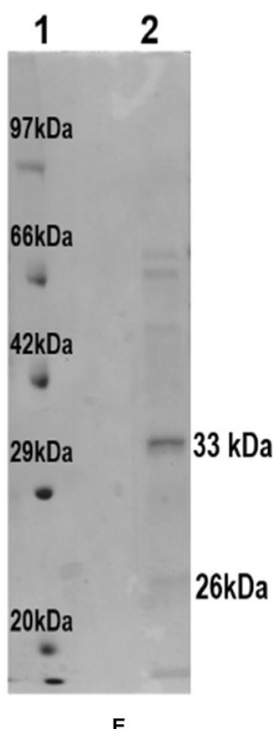

Fig. 2 Pseudomonas secretome induced cytotoxic effects and inhibited the migration of $\mathrm{HDF}$ and HaCaT cells. a, b Effects of secretory proteins from Pseudomonas culture conditioned medium on cell survival of $\mathrm{HDF}$ cells and $\mathrm{HaCaT}$ cells with concentration ranging from 2.5 to $10 \mathrm{mg} / \mathrm{mL}$ by MTT assay after $48 \mathrm{~h}$. c, d Effect of secretory proteins from Pseudomonas culture conditioned medium on cell migration at concentration 2.0 and $1.5 \mathrm{mg} / \mathrm{mL}$ on HDF cells and

\section{Pseudomonas secretome induced cytotoxic effects and inhibited migration of HDF and $\mathrm{HaCaT}$ cells}

Different concentrations of lyophilized $P$. aeruginosa culture condition medium ranging from 2.5 to $10 \mathrm{mg} / \mathrm{mL}$ were tested on $\mathrm{HDF}$ and $\mathrm{HaCaT}$ cells for their cytotoxic effects
$\mathrm{HaCaT}$ cells at different time intervals. Percentage of cell survival and cell migration was calculated and data are shown as mean $\pm \mathrm{SD}$, $* * * p<0.001$ compared to control. e Profiling of secretory proteins from Pseudomonas culture conditioned medium by $12 \%$ SDS-PAGE. Lane 1: protein molecular weight marker (Medium range, GeNei, India), Lane 2: secretory proteins from Pseudomonas culture conditioned medium.

by MTT assay. The crude secretory proteins from culture conditioned medium of high biofilm-forming strain showed cytotoxicity with $\mathrm{IC}_{50}$ value of 3.89 and $5.81 \mathrm{mg} / \mathrm{mL}$ on $\mathrm{HDF}$ and HaCaT cells, respectively (Fig. 2a, b).

HDF $(2.0 \mathrm{mg} / \mathrm{mL})$ and $\mathrm{HaCaT}$ cells $(1.5 \mathrm{mg} / \mathrm{mL})$ were treated with crude secreted proteins from culture conditioned 
Table 1 Mass spectroscopic profiles of pseudolysin and protease IV proteins from Pseudomonas culture conditioned medium (peptides that matched are in bold).

\begin{tabular}{|c|c|c|c|c|}
\hline Sample & Mascot score & Protein name & Peptide sequence & MW \\
\hline $\begin{array}{l}P . \text { aeruginosa culture } \\
\text { conditioned medium }\end{array}$ & 2157 & Pseudolysin & $\begin{array}{l}\text { GGPGGNQKIG KYTYGSDYGP LIVNDRCEMD DGNVITVDMN } \\
\text { SSTDDSKTTP FRFACPTNTY KQVNGAYSPL NDAHFFGGVV } \\
\text { FKLYRDWFGT SPLTHKLYMK VHYGRSVENA YWDGTAMLFG } \\
\text { DGATMFYPLV SLDVAAHEVS HGFTEQNSGL IYRGQSGGMN } \\
\text { EAFSDMAGEA AEFYMRGKND FLIGYDIKKG SGALRYMDQP } \\
\text { SRDGRSIDNA SQYYNGIDVH HSSGVYNRAF YLLANSPGWD } \\
\text { TRKAFEVFVD ANRYYWTATS NYNSGACGVI RSAONRNYSA } \\
\text { ADVTRAFSTV GVTCPSAL }\end{array}$ & 53882 \\
\hline $\begin{array}{l}\text { P. aeruginosa culture } \\
\text { conditioned medium }\end{array}$ & 975 & $\begin{array}{l}\text { Lysyl } \\
\text { endopeptidase } \\
\text { (protease IV) }\end{array}$ & $\begin{array}{l}\text { QVSTFADSLY KAGYRDGFGA SGSCEVDAVC ATQSGTRAYD } \\
\text { NATAAVAKMV FTSSADGGSY ICTGTLLNNG NSPKRQLFWS } \\
\text { AAHCIEDQAT AATLQTIWFY NTTQCYGDAS TINQSVTVLT } \\
\text { GGANILHRDA KRDTLLLELK RTPPAGVFYQ GWSATPIANG } \\
\text { SLGHDIHHPR GDAKKYSQGN VSAVGVTYDG HTALTRVDWP } \\
\text { SAVVEGGSSG SGLLTVAGDG SYQLRGGLYG GPSYCGAPTS } \\
\text { QRNDYFSDFS GVYSQISRYF AP }\end{array}$ & 48582 \\
\hline
\end{tabular}

medium of high biofilm-forming strain to test cell migration in a scratch assay. Kinetic analysis in treated cells showed a significant decrease in wound closure when compared to untreated and vehicle control (TSB) (Fig. 2c, d). Besides, high biofilm-forming strain showed a significant reduction in cell migration in both HDF and HaCaT cells. Protein-treated HDF and $\mathrm{HaCaT}$ cells showed relatively slower migration of $50 \%$ and $67 \%$, respectively, whereas vehicle controls showed $100 \%$ cell migration at the end of 48 and $24 \mathrm{~h}$ similar to controls. These results suggest that Pseudomonas secretome may possess cytotoxic and anti-migratory properties.

\section{Profiling of secretory proteins in P. aeruginosa culture conditioned medium}

The lyophilized $P$. aeruginosa culture conditioned medium of high biofilm-forming strain was subjected to SDS-PAGE to visualize secretory proteins. Secretory proteins of high biofilm-forming strain with significant cytotoxicity and reduced cell migration potential showed prominent band with the molecular mass of $33 \mathrm{kDa}$ and less intensified band with the molecular mass of $26 \mathrm{kDa}$ (Fig. 2e). These bands were isolated and subjected to peptide mass finger printing LC/MS/MS analysis and tryptic digested peptides, which led to the identification of pseudolysin and protease IV. Peptide matched with pseudolysin and protease IV with a significant score of 2157 and 975, respectively (Table 1).

\section{Ammonium sulfate precipitated and purified fractions containing pseudolysin and protease IV modulate cytotoxicity and migration in cell types}

Extraction of pseudolysin and protease IV from $P$. aeruginosa culture conditioned medium was performed by ammonium sulfate precipitation method. The extracted secretory proteins were separated on a $12 \%$ SDS-PAGE (Fig. S3a). Upon ammonium sulfate precipitation, two major proteins corresponding to 33 and $26 \mathrm{kDa}$ were observed in abundance along with proteins with $<20 \mathrm{kDa}$ in minor amounts. Mass spectrometry analysis of these abundant proteins revealed the peptides to be pseudolysin and protease IV with the best score of 3350 and 1061, respectively (Table S2). Due to close molecular weights between these two proteins, the individual isolation or separation of proteins was not achieved even after sizeexclusion chromatography. Further to assess the cytotoxic effects of these secretory proteins on HDF and HaCaT cells, we performed concentration dependent MTT assay. On $\mathrm{HDF}$, cytotoxic effects were observed with an $\mathrm{IC}_{50}$ value of $22.21 \mu \mathrm{g} / \mathrm{mL}$ (Fig. S3b), while $\mathrm{IC}_{50}$ value was found to be $11.23 \mu \mathrm{g} / \mathrm{mL}$ (Fig. S3c) in HaCaT cells. Under normal culture conditions, HDF cells required $48 \mathrm{~h}$ for wound closure and treating cells with these fractions with concentrations of 5.0 and $7.5 \mu \mathrm{g} / \mathrm{mL}$ significantly hindered migration to $70 \%$ and $48 \%$, respectively (Fig. S3d). Antimigratory properties of these protein fractions were also observed in $\mathrm{HaCaT}$ cells where only $45 \%$ of wound closure at the end of $24 \mathrm{~h}$ post wounding $(5.0$ and $7.5 \mu \mathrm{g} / \mathrm{mL})$, whereas control showed complete wound closure at the end of $24 \mathrm{~h}$ (Fig. S3e).

\section{Expression of recombinant virulence proteins}

The las $B$ gene encoding for the mature active pseudolysin and prpL gene coding for the mature active protease IV were cloned separately into the pET 28 a $(+)$ vector under the control of $\mathrm{T} 7$ promoter. Recombinant virulence proteins were efficiently expressed as soluble fraction in $E$. coli BL21 (DE3) cells reaching the optimum levels at $4 \mathrm{~h}$ after the induction with IPTG (Fig. 3a, c). The purified 
Fig. 3 Recombinant mature pseudolysin and protease IV separated on $12 \%$ SDS-PAGE and representative sequence of peptides identified by MS/MS analysis. a Isolation of recombinant $33 \mathrm{kDa}$ mature pseudolysin (uninduced and induced) expressed in E. coli BL21 (DE3) cells. Lane 1: protein molecular weight marker (Thermo ScientificTM 26610, USA), Lane 2: uninduced protein sample, Lane 3: induced protein sample. b Purified recombinant mature $33 \mathrm{kDa}$ pseudolysin on $12 \%$ SDSPAGE. Lane 1: protein molecular weight marker, Lane 2: $33 \mathrm{kDa}$ mature pseudolysin. c Isolation of recombinant $26 \mathrm{kDa}$ mature protease IV (uninduced and induced) expressed in E. coli BL21 (DE3) cells. Lane 1: protein molecular weight marker, Lane 2: uninduced protein sample, Lane 3: induced protein sample. d Purified recombinant $26 \mathrm{kDa}$ mature protease IV on $12 \%$ SDS-PAGE. Lane 1: protein molecular weight marker, Lane 2: $26 \mathrm{kDa}$ mature protease IV. e, f Peptide sequence obtained by MS/MS analysis of recombinant pseudolysin and protease IV, respectively.

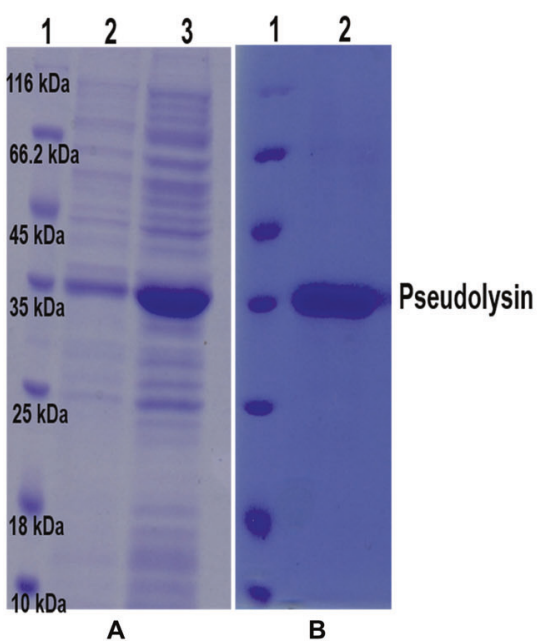

1 MKKVSTLDLL FVAIMGVSPA AFAADLIDVS KLPSKAAQGA PGPVTLQAAV 51 GAGGADELKA IRSTTLPNGK QVTRYEOFHN GVRVVGEAIT EVKGPGKSVA 101 AQRSGHEVAN IAPDLGSTT AAVSAEQVLA OAKSLKAOGR KTENDKVELV

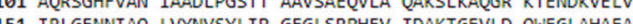
TI IRLENIAQ LVMSYIP GEGLSRPHFV IDAKTGEVLD QNEGLAHAEA

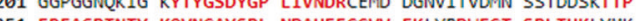
251 FRFACPTNTY KQUNGAYSPL NDAHFFGGW FKLYRDWFGT SPLTHKLYMK 301 VHYGRSVENA YWDGTANLFG DGATMFYPLV SLDVAAHEVS HGFTEQNSGL 351 IYRGQSGGINN EAFSDMAGEA AEFYMRGKND FLIGYDIKKG SGALRYMDQP 401 SRDGRSIDNA SQYYNGIDVH HSSGVYNRAF YLLANSPGWD TRKAFEVFVD 451 ANRYYWTATS NYNSGACGVI RSAQNRNYSA ADVTRAFSTV GVTCPSAL

SVENAYWDGTAMLFGDGATMFYPLVSLDVAAHEVSHGFTEQNSGLIYR
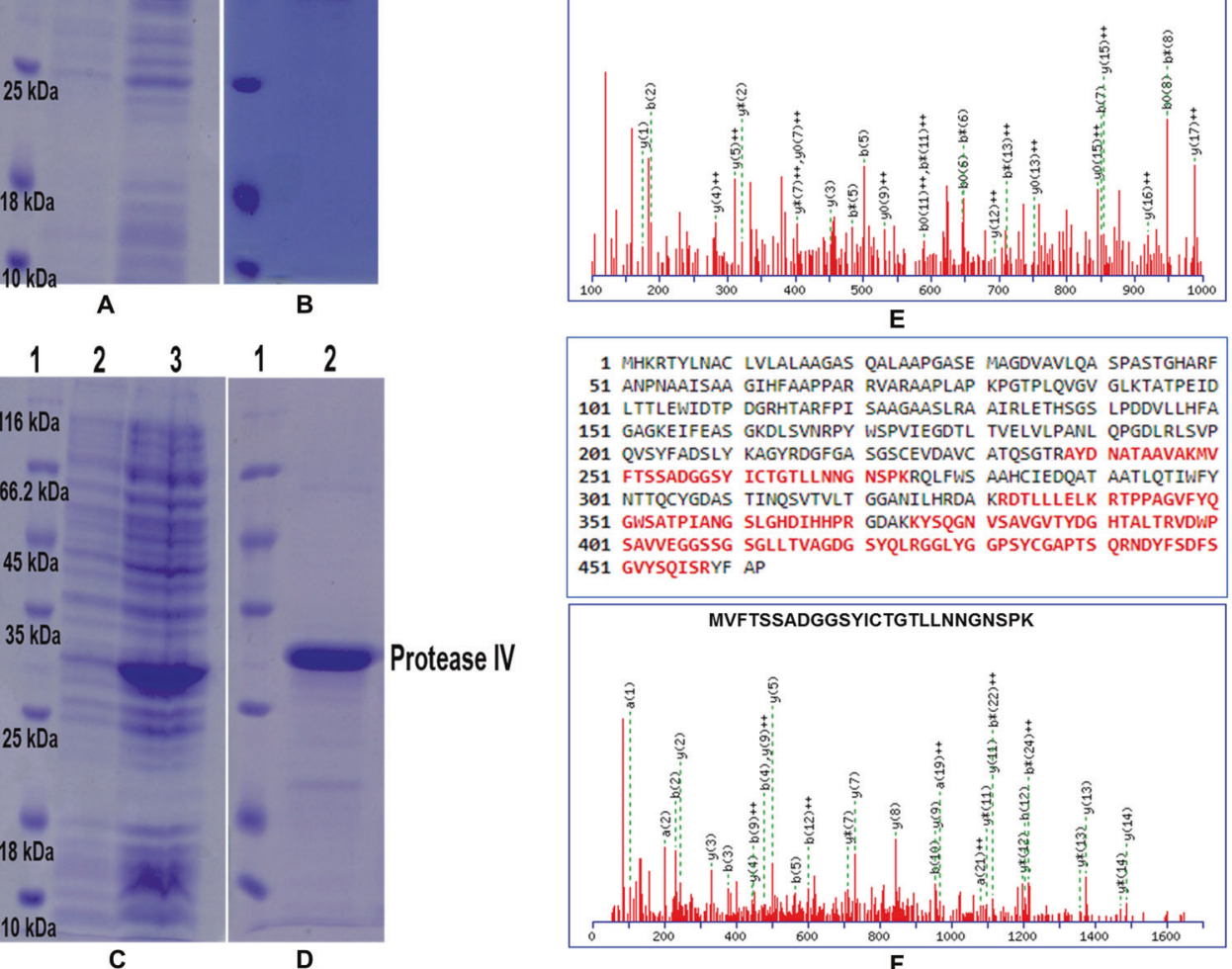

1 MHKRTYLNAC LVLALAAGAS QALAAPGASE MAGDVAVLQA SPASTGHARF 51 ANPNAAISAA GIHFAAPPAR RVARAAPLAP KPGTPLQVGV GLKTATPEID 151 GAGKEIFEAS GKDLSVNRPY WSPVIEGDTL TVELVLPANL QPGDLRLSVP 201 QVSYFADSLY KAGYRDGFGA SGSCEVDAVC ATQSGTRAYD NATAAVAKMV 251 FTSSADGGSY ICTGTLLNNG NSPKRQLFWS AAHCIEDQAT AATLQTIWFY 301 NTTOCYGDAS TINQSVTVLT GGANILHRDA KRDTLLLELK RTPPAGVFYQ 351 GUSATPTANG SLGHDIHHPR GDAKKYSOGN VSAVGVTYDG HTALTRVDIP 401 SAVVEGGSSG SGLLTVAGDG SYOLRGGLYG GPSYCGAPTS ORNDYFSDFS 451 GVYSQISRYF AP

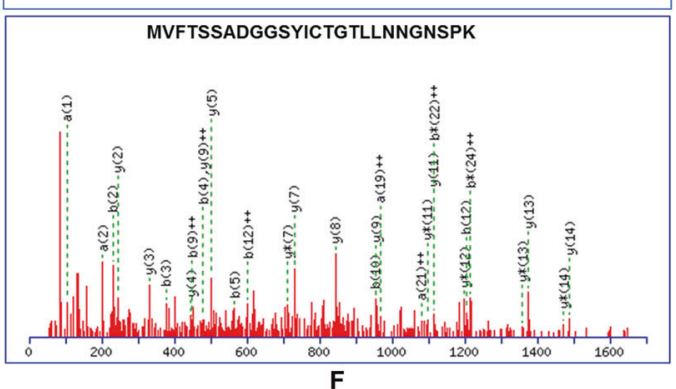
101 LTTLEWIDTP DGRHTARFPI SAAGAASLRA AIRLETHSGS LPDDVLLHFA recombinant proteins were separated on a $12 \%$ SDS-PAGE (Fig. 3b, d) and the bands were identified as pseudolysin and protease IV based on LC/MS/MS analysis (Fig. 3e, f).

\section{Recombinant pseudolysin and protease IV significantly affected the survival of fibroblasts and HaCaT cells}

To evaluate the cytotoxic potential of recombinant pseudolysin and protease IV of $P$. aeruginosa in time-dependent manner, HDF and $\mathrm{HaCaT}$ cells were treated with various concentrations. Percentage of cell survival was assessed by MTT assay $48 \mathrm{~h}$ post incubation. Recombinant pseudolysin was treated on HDF cells at a concentration ranging from 10 to $40 \mu \mathrm{g} / \mathrm{mL}$ (Fig. $4 \mathrm{a}$ ) and on $\mathrm{HaCaT}$ cells at a concentration ranging from 5.0 to $25 \mu \mathrm{g} / \mathrm{mL}$ (Fig. $4 \mathrm{~b}$ ). HDF cells showed $\mathrm{IC}_{50}$ value of $29.29 \mu \mathrm{g} / \mathrm{mL}$, and it was $13.14 \mu \mathrm{g} / \mathrm{mL}$ for $\mathrm{HaCaT}$ cells. Recombinant protease IV was treated on HDF cells at a concentration ranging from 1 to $10 \mu \mathrm{g} / \mathrm{mL}$ (Fig. 4c) and on $\mathrm{HaCaT}$ cells at a concentration ranging from 1 to $10 \mu \mathrm{g} / \mathrm{mL}$ (Fig. $4 \mathrm{~d}$ ). $\mathrm{IC}_{50}$ values for protease IV for HDF and
HaCaT cells were 4.84 and $3.91 \mu \mathrm{g} / \mathrm{mL}$, respectively. These results suggested that the recombinant pseudolysin and protease IV were capable of inducing the cytotoxicity on the cells involved in wound healing.

\section{Recombinant pseudolysin and protease IV inhibited cell migration}

Recombinant pseudolysin and protease IV showed a significantly inhibited cell migration on HDF and $\mathrm{HaCaT}$ cells. Quantitative analysis at different time intervals showed a progressive decrease in the wound closure rate in recombinant pseudolysin and protease IV treated cells when compared to control. The concentration of recombinant pseudolysin used was $10 \mu \mathrm{g} / \mathrm{mL}$ for HDF (Fig. 4e) and $5 \mu \mathrm{g} /$ $\mathrm{mL}$ for $\mathrm{HaCaT}$ cells (Fig. 4f). A significant reduction in wound closure rate of $65 \%$ on HDF cells and $36 \%$ on $\mathrm{HaCaT}$ cells was observed after $24 \mathrm{~h}$ post wounding compared to controls. HDF and HaCaT cells were also treated with recombinant protease IV at $2 \mu \mathrm{g} / \mathrm{mL}$ (Fig. 4e) and $1.5 \mu \mathrm{g} / \mathrm{mL}$ (Fig. 4f), respectively. Protease IV showed 

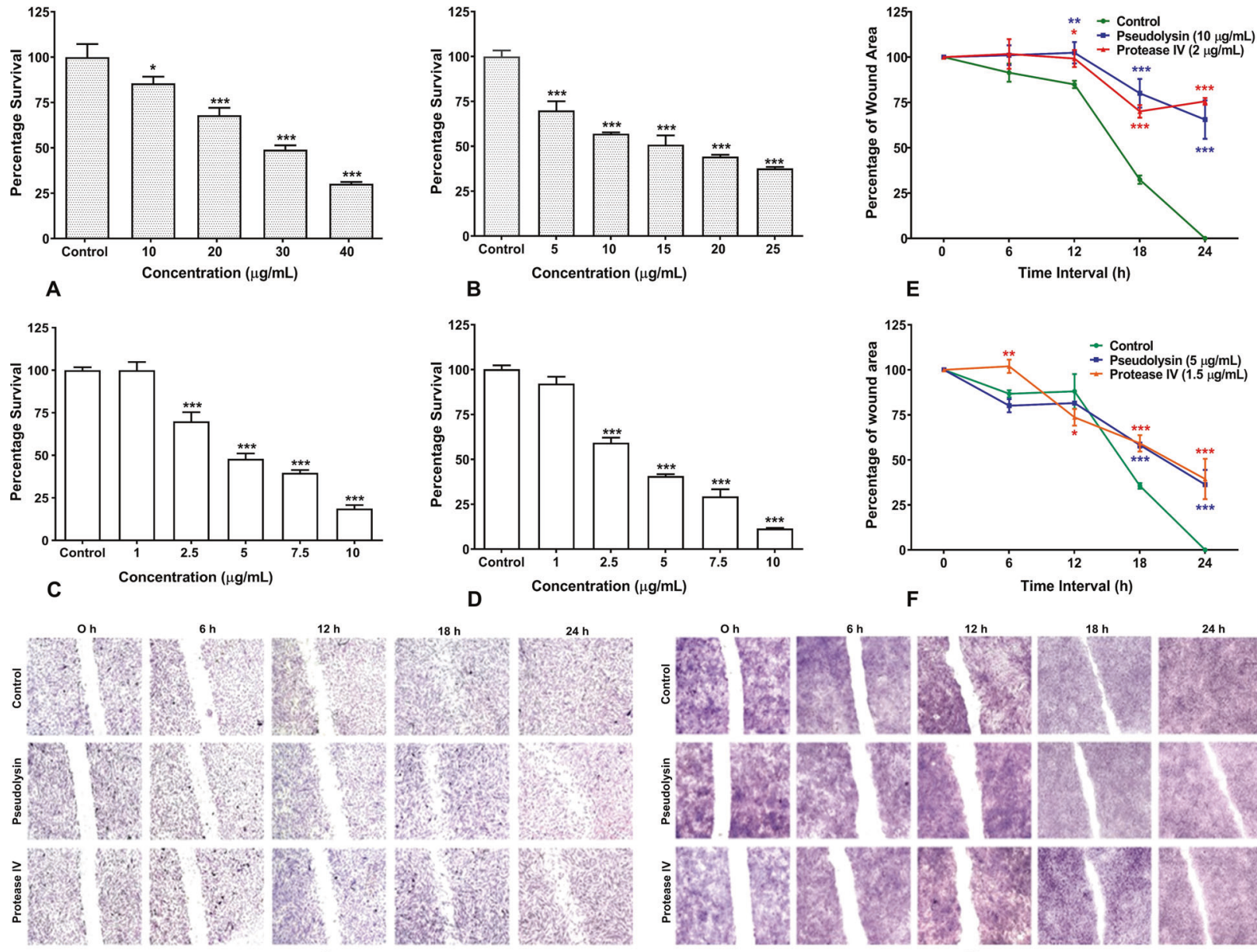

G

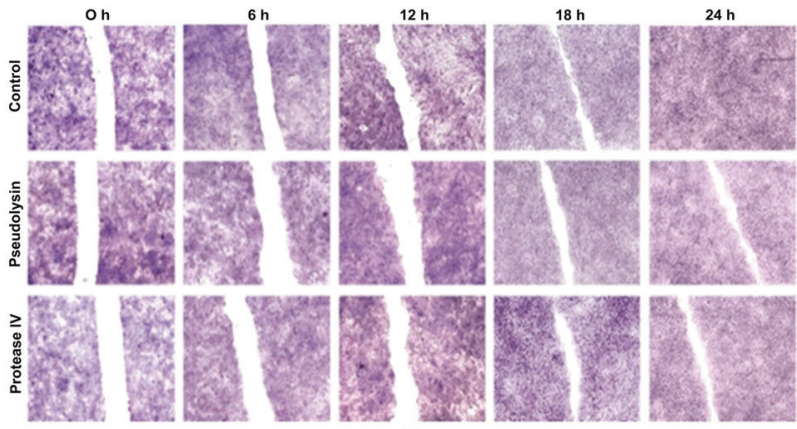

H

Fig. 4 Recombinant pseudolysin and protease IV significantly affected survival and inhibited cell migration. a-d Cytotoxic potential of recombinant pseudolysin and protease IV on HDF cells and $\mathrm{HaCaT}$ cells. e, f Effect of recombinant pseudolysin and protease IV on

cell migration on HDF cells and HaCaT cells. g, h Representative images of cell migration of $\mathrm{HDF}$ cells and $\mathrm{HaCaT}$ cells at various time points. Percentage of cell survival and cell migration was calculated and data are shown as mean $\pm \mathrm{SD}, * * * p<0.001$ compared to control.

significant reduction in wound closure rate of $75 \%$ for $\mathrm{HDF}$ cells and 39\% for $\mathrm{HaCaT}$ cells. Taken together, our results indicated that pseudolysin and protease IV inhibited the migratory property of $\mathrm{HDF}$ and $\mathrm{HaCaT}$ cells.

\section{Recombinant pseudolysin and protease IV inhibit angiogenic activities}

We investigated the effect of recombinant pseudolysin and protease IV on angiogenesis using HUVEC cells. Initial assessment of cytotoxicity by pseudolysin and protease IV was assessed by performing MTT assay using HUVECs. HUVECs were treated with recombinant pseudolysin and protease IV at a concentration ranging from 2 to $8 \mu \mathrm{g} / \mathrm{mL}$ (Fig. 5a) and 1 to $4 \mu \mathrm{g} / \mathrm{mL}$, respectively (Fig. 5b), and the $\mathrm{IC}_{50}$ values of 5.19 and $1.65 \mu \mathrm{g} / \mathrm{mL}$, respectively, were obtained. In vitro cell migration analysis of HUVEC cells showed a significant reduction in wound closure in cells treated with pseudolysin at $1 \mu \mathrm{g} / \mathrm{mL}$ and protease IV at $0.5 \mu \mathrm{g} / \mathrm{mL}$ when compared to control at the end of $24 \mathrm{~h}$ post wounding (Fig. 5c). Furthermore, HUVECs tube formation (Fig. 5d, e) and sprouting (Fig. 5f-h) were significantly inhibited by both pseudolysin and protease IV. These results demonstrate that the pseudolysin and protease IV have an ability to inhibit angiogenesis in vitro.

\section{Wound contraction assays indicated a significant delay in the wound-healing process by recombinant pseudolysin and protease IV}

After confirming cytotoxic and anti-migratory properties of recombinant pseudolysin and protease IV, we investigated the influence of these proteins on wound contraction in in vivo mouse models. Characterization of carbopol 934 gel impregnated with pseudolysin and protease IV was performed after $2 \mathrm{~h}$ of gel preparation. Functional studies confirmed the texture 


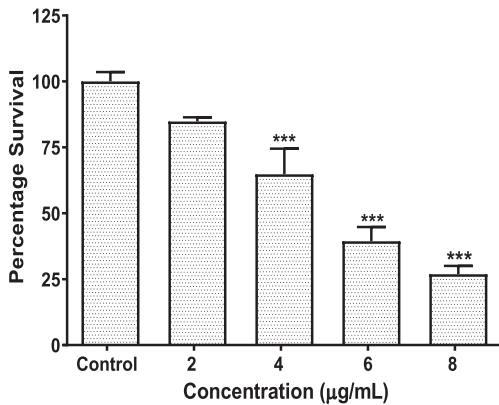

A

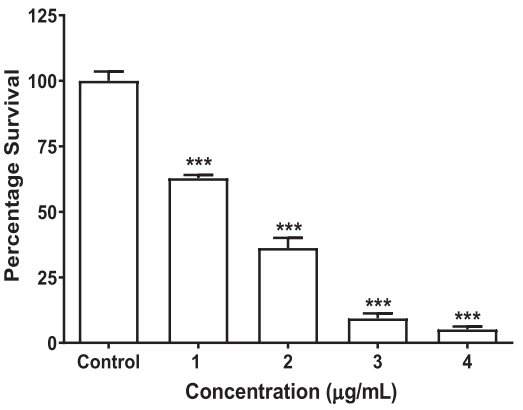

B

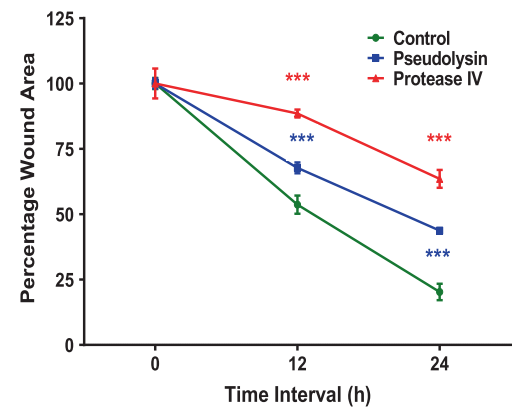

C

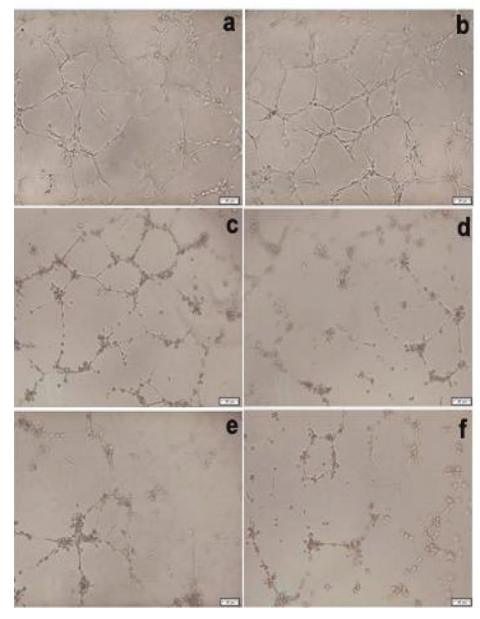

D

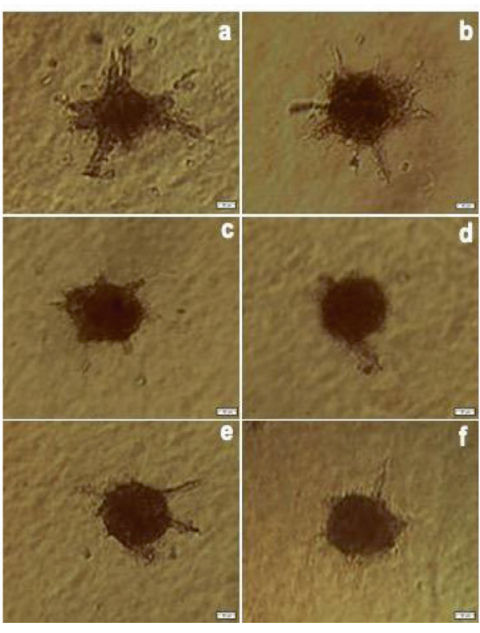

$\mathbf{F}$

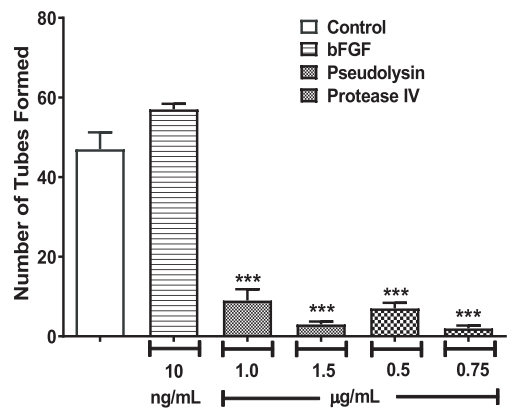

E

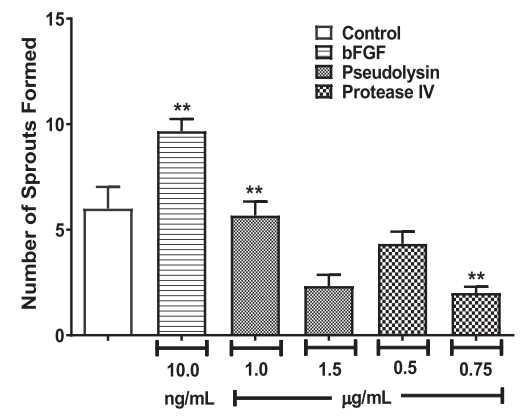

G

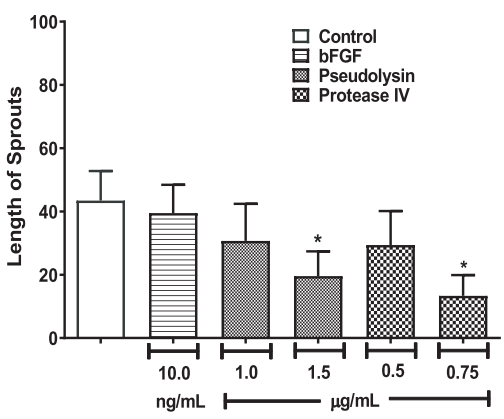

H
Fig. 5 Recombinant pseudolysin and protease IV inhibited angiogenic activities. a, b Cytotoxic potential of recombinant pseudolysin and protease IV on human endothelial (HUVEC) cells. Percentage of cell survival was calculated and data were shown as mean $\pm \mathrm{SD}, * * * p<$ 0.001 compared to control. c Effect of recombinant pseudolysin and protease IV on the migration of HUVECs. The percentage of wound

of carbopol 934 gel as homogenous, translucent, and smooth. The $\mathrm{pH}$ was observed to be ranging from 7.0 to 7.4. Carbopol 934 powder formed a gel upon mixing with recombinant pseudolysin and protease IV, facilitating convenient for topical administration. The protein content was found to be $95.37 \pm$ $2.12 \%$ for pseudolysin gel and $96.52 \pm 3.74 \%$ for protease IV gel indicating the stability and content uniformity in the gel. The characteristics of carbopol are represented in Table 2. closure was calculated at different time intervals. d, e Tube formation assay. f-h Sprouting assay. a Control, b bFGF $10 \mathrm{ng} / \mathrm{mL}$, c pseudolysin $1.0 \mu \mathrm{g} / \mathrm{mL}$, d pseudolysin $1.5 \mu \mathrm{g} / \mathrm{mL}$, e protease IV $0.5 \mu \mathrm{g} / \mathrm{mL}$, f protease IV $0.75 \mu \mathrm{g} / \mathrm{mL}$. Data were shown as mean $\pm \mathrm{SD}, * * * p<0.001$ compared to control.

Wound healing progression was monitored by taking digital images on every alternative day until complete wound closure (Fig. 6a). The control and vehicle control showed progressive healing and the complete wound closure was observed on 21st day post wounding. Pseudolysin and protease IV significantly $(p<0.001)$ delayed wound contraction when compared to vehicle control and control groups (Fig. 6b). Pseudolysin treated animals and protease IV treated 
Table 2 Characterization of carbopol gel 934.

Fig. 6 Wound contraction assays indicated significant delay in the wound-healing process by recombinant pseudolysin and protease IV. a Representative photographic images of control, vehicle control, pseudolysin, and protease IV treated groups showing a reduction in wound area post wounding. b Wound contraction kinetics of different experimental groups expressed as percentage of the wound area. Images were taken every alternative day and analyzed by ImageJ software. Data represented are mean \pm SEM. $* * * p<0.001$ compared to control.

\begin{tabular}{llllll}
\hline Appearance & Transparency & Homogeneity & Texture & $\mathrm{pH}$ & Drug content \\
\hline \multirow{3}{*}{ if } & Translucent & $\begin{array}{l}\text { Highly homogeneous } \\
\text { (no crystals observed) }\end{array}$ & Smooth & $7.0-7.4$ & $95.37 \pm 2.12 \%$ \\
& & & & $96.52 \pm 3.74 \%$ \\
\hline
\end{tabular}
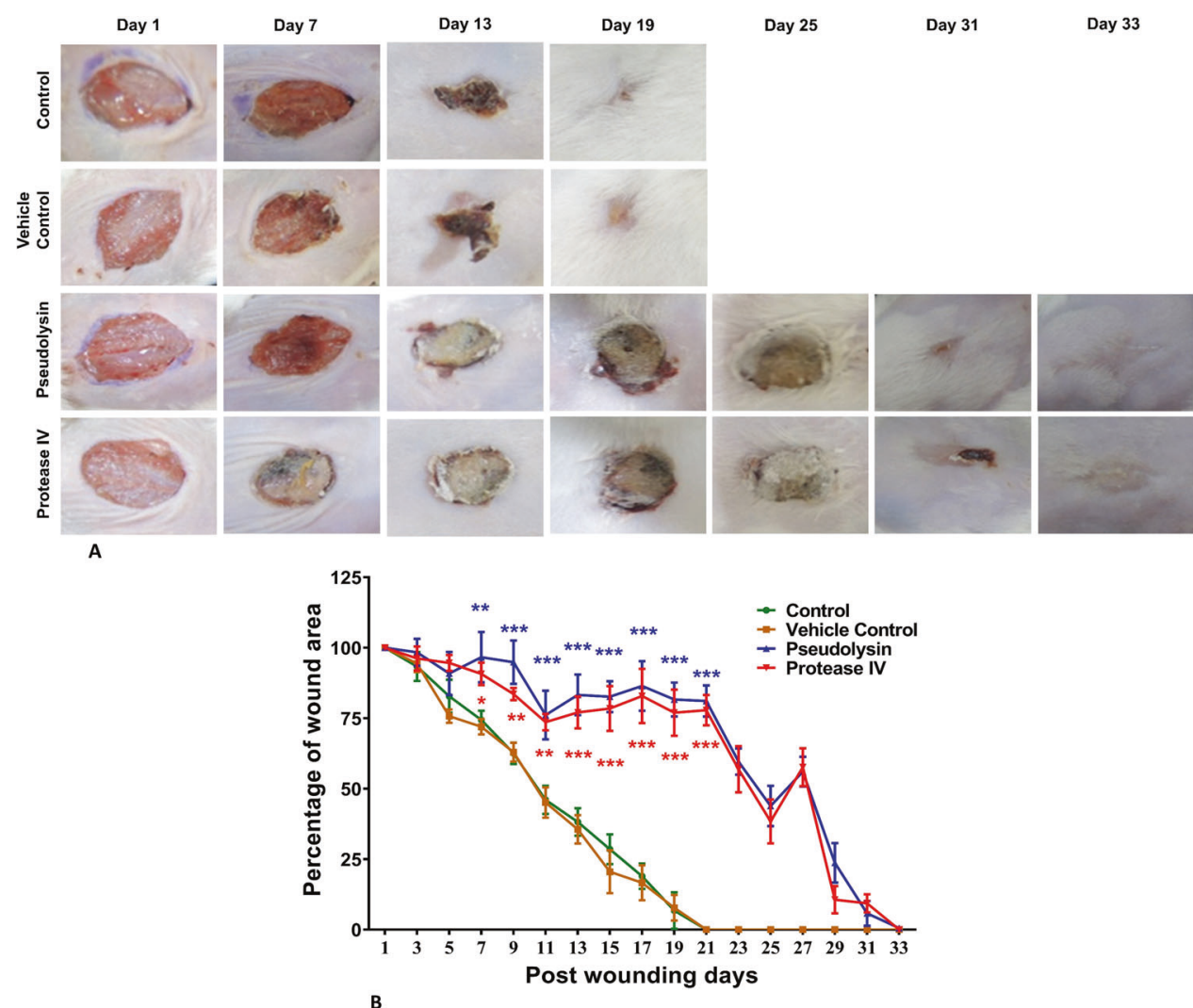

animals took 31 and 33 days, respectively, for the complete closure of the wound. During the entire study period, wounded animals were healthy and there were no adverse effects.

Initial histological analysis of granulation tissues of control and treated groups was performed after H\&E staining. Wound healing progression was analyzed at different time intervals of 6th, 12th, and 18th day of post wounding (Fig. 7a). On 6th, 12 th, and 18th day of wound healing, both the control and vehicle control showed a similar response to edema and on 18 th day it was present only on the wound margin. However, in case of the pseudolysin treated group on 6th and 12th day, the edema was present in more than $50 \%$ of the tissues analyzed, but on the 18th day, the edema was present at the wound boundaries, whereas protease IV on 6th, 12th, and 18th day, the edema was present in more than $50 \%$ of the tissue observed. Presence of leukocytes in both the control groups was mild, while in the case of pseudolysin and protease IV treated groups a moderate number of cells were observed throughout the indicated time points. This suggested a pro-inflammatory condition in treated groups. The presence of granulation tissues and fibroblasts in the pseudolysin and protease IV treated animals showed less evidence compared to the vehicle control and control. While, in control and vehicle control animals, epithelial thickening and cell migration were observed and these were absent in pseudolysin and protease IV treated animals even after the 18th day post wounding. Histological evaluation for collagen was performed on the granulation tissues by MT staining (Fig. 7b). On the 6th day post wounding, both the control and vehicle control groups showed similar levels of collagen present at the focal boundaries of fibroblasts and also around new capillaries. However, pseudolysin and protease IV treated groups did not show any evidence of collagen synthesis. On the 18th day post wounding, a moderate amount of collagen levels was observed in untreated and vehicle control groups, whereas mild collagen was observed in pseudolysin treated groups and there was no evidence of collagen in protease IV treated groups.

Image analysis of MT stained granulation tissues showed a significant reduction in collagen levels in pseudolysin and 
Fig. 7 Representative images of histology of granulation tissue of different experimental groups at days 6 , 12 , and 18 post wounding at $\times 10$ magnification. a $H \& E$ staining. b Masson trichrome staining. Scale bars: $100 \mu \mathrm{m}$. c Quantitative analysis of Masson trichrome stained tissue sections by digital image analysis using TissueQuant software. Data represented are mean \pm SEM. *** $p<0.001$ compared to control.
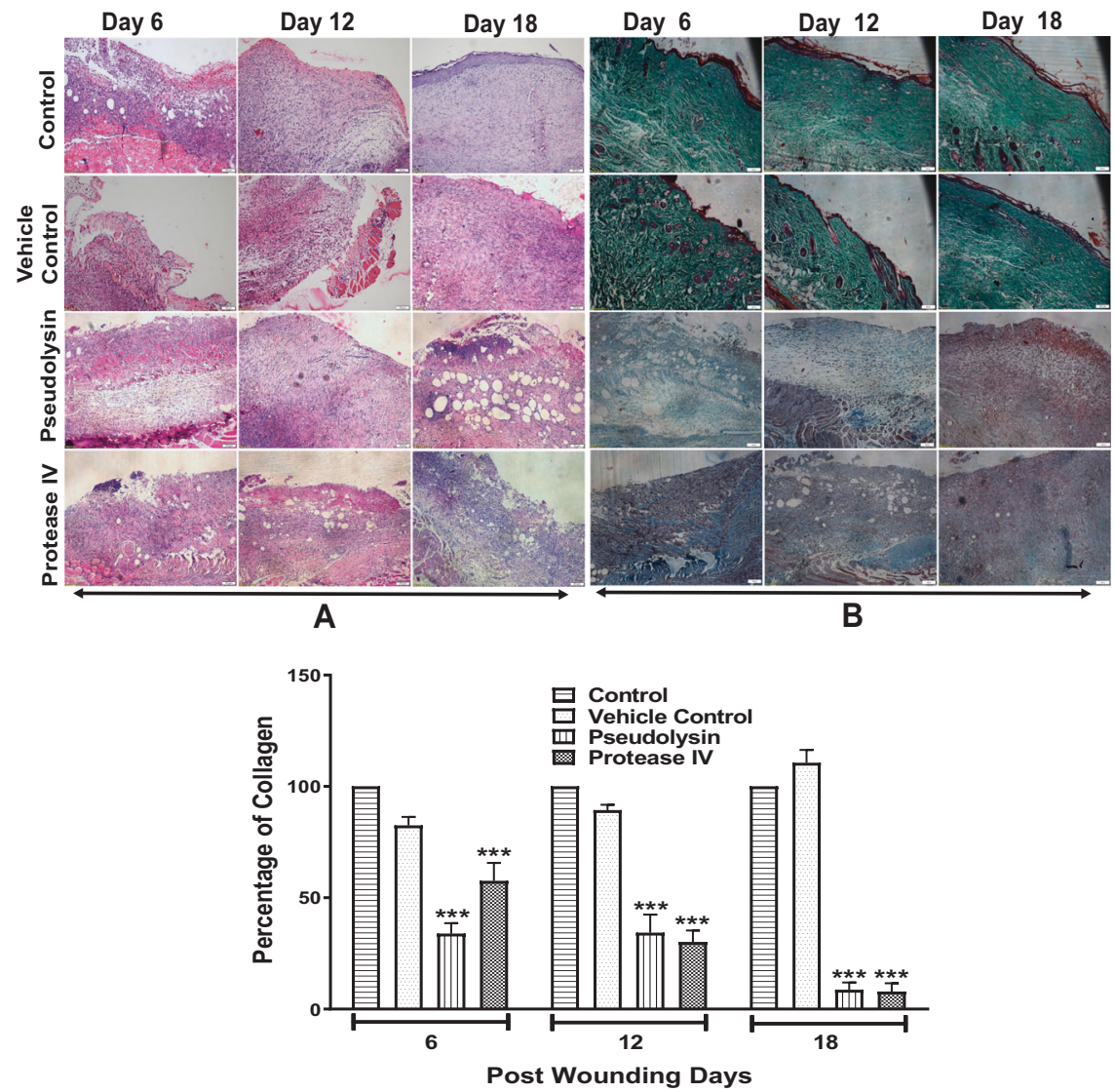

C protease IV treated groups when compared to vehicle control and control. We observed a $66.2 \%$ reduction in collagen levels on day $6,65.7 \%$ reduction on day 12 , and $91.3 \%$ reduction on day 18 in pseudolysin treated group, while in protease IV treated group the corresponding values were $42.5 \%, 69.8 \%$, and $92.1 \%$ reduction on days 6,12 , and 18 , respectively (Fig. 7c).

Ki67 and CD31 staining was performed to investigate cell proliferation and neo-angiogenesis (Fig. 8a, b). We observed a significant decrease in the proliferation of fibroblasts and keratinocytes when compared to control groups. Vascular endothelial cell proliferation was detected in granulation tissues of control groups on 6th day post wounding with the subsequent increase in the number of proliferating endothelial cells resulting in vessel rich granulation tissue on 12th and 18th day post wounding, whereas significantly less vascularization was observed throughout the wound-healing process in recombinant protein-treated groups. A significant decrease in micro vessel density was observed in both pseudolysin and protease IV treated animals compared to the untreated and vehicle control groups.

Pseudolysin and protease IV treatment resulted in a significant reduction in proliferation of fibroblasts and keratinocytes in granulation tissues when compared to vehicle control and control groups. Proliferation index was $9.6 \%$ on day $6,7.9 \%$ on day 12 , and $4.2 \%$ on day 18 in pseudolysin treated group, while in protease IV treated group we observed $4.5,3.6$, and $0.9 \%$ on days 6,12 , and 18 when compared to control group (Fig. 8c).

Similarly, image analysis was performed on CD31 stained granulation tissues to measure the vessel density (Fig. 8d). We observed a significant reduction in vessel density in granulation tissues treated with pseudolysin and protease IV when compared to vehicle control and control groups. There was 51 and $72.6 \%$ reduction in vessel density on day $6(p<0.001), 62.8$ and $75.4 \%$ reduction on day $12(p<0.001)$, and 86.8 and $90.8 \%$ reduction on day 18 $(p<0.001)$ in pseudolysin and protease IV treated groups compared to control.

Furthermore, we estimated hydroxyproline levels in granulation tissues to assess collagen content. The results of the hydroxyproline concentration in the granulation tissue displayed a similar pattern to those results observed in the histological analysis with reduced collagen content in proteintreated groups (Fig. 9a). The rise in hydroxyproline content was observed on days 6 and 12 and gradually stabilized on the 18th day in vehicle control and control groups. On the other hand, granulation tissues of the pseudolysin and 


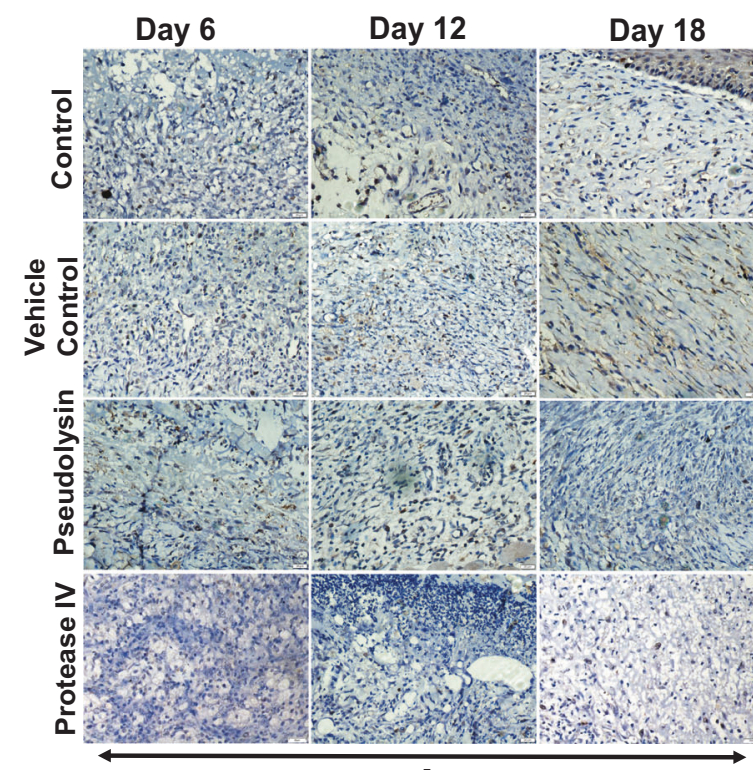

A

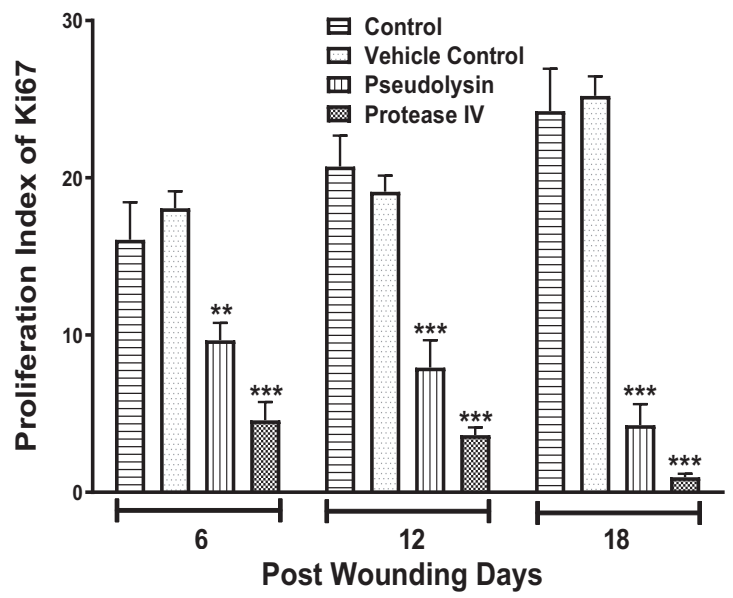

C

Fig. 8 Representative images of immunohistochemical examination of granulation tissue at days 6,12 , and 18 post wounding at $\times \mathbf{1 0}$ magnification. a Granulation tissues were stained with Ki67. b Granulation tissues were stained with CD31. Scale bars: $100 \mu \mathrm{m}$.

protease IV treated animals showed significantly lower levels of hydroxyproline at all the time points $(p<0.001)$.

\section{Pseudolysin and protease IV enhance oxidative stress and pro-inflammatory milieu}

Oxidative stress has been reported to modulate wound healing. Hence, we subsequently estimated lipid peroxidation levels as a marker of oxidative stress. On 6th day of post wounding, there was a twofold increase in the TBARS levels in the pseudolysin and protease IV treated tissues compared to vehicle control and untreated groups. On the

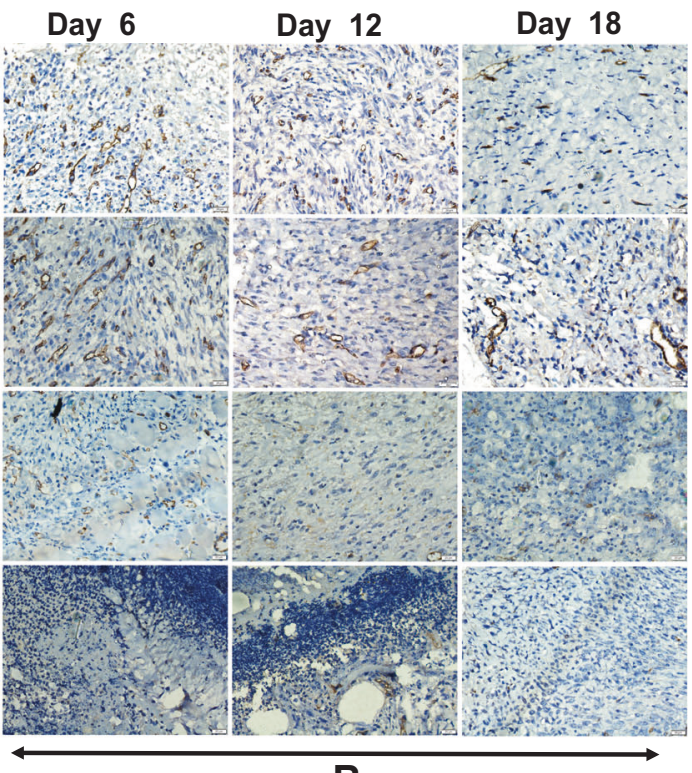

B

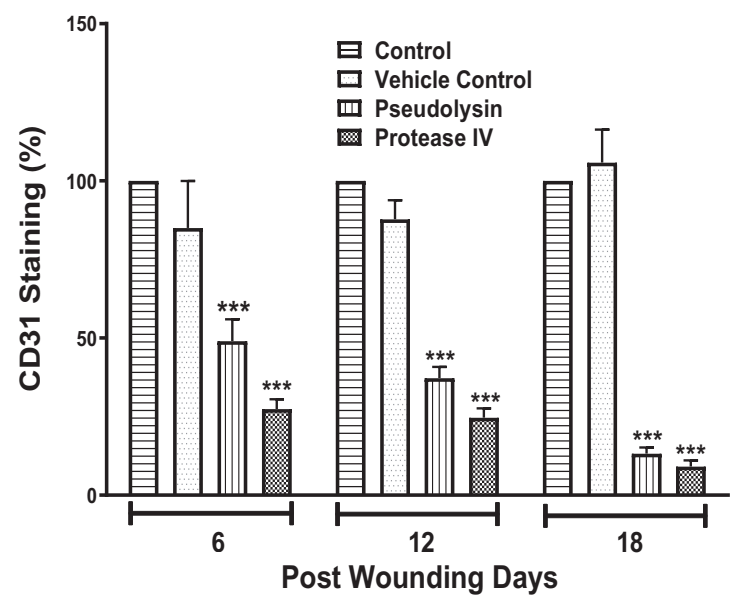

c, d Proliferation index of Ki67 stained tissue sections and quantification of neo vessel formation by digital image analysis using TissueQuant software. Data represented are mean \pm SEM. $* * * p<$ 0.001 compared to control.

12th day of post wounding, there was a 2.5 -fold and 2.8 fold increase in the TBARS levels in the pseudolysin and protease IV treated tissues, respectively, compared to both the control groups. On the 18th day of post wounding, there was a 1.8-fold and 2.4-fold increase in the TBARS levels in the pseudolysin and protease IV treated tissues, respectively, compared to both the control groups (Fig. 9b). A significant increase $(p<0.001)$ in TBARS levels was observed in granulation tissues of treated groups on all the post wounding days compared to both control groups.

As we observed the infiltration of leukocytes in animals treated with pseudolysin and protease IV, we tested for IL-6 
Fig. 9 Quantification using biochemical tests.

a Hydroxyproline content (hydroxyproline/mg of granulation tissue). b Lipid peroxidation levels (lipid peroxidation $/ \mathrm{mg}$ of granulation tissue) of control, vehicle control, pseudolysin, and protease IV treated groups upon wound healing at different time points. c IL-6 levels by ELISA. Change in parameters compared to controls was expressed as fold change at different post wounding days. Data represented are mean $\pm \mathrm{SD}$, $* * * p<0.001$ compared to control.

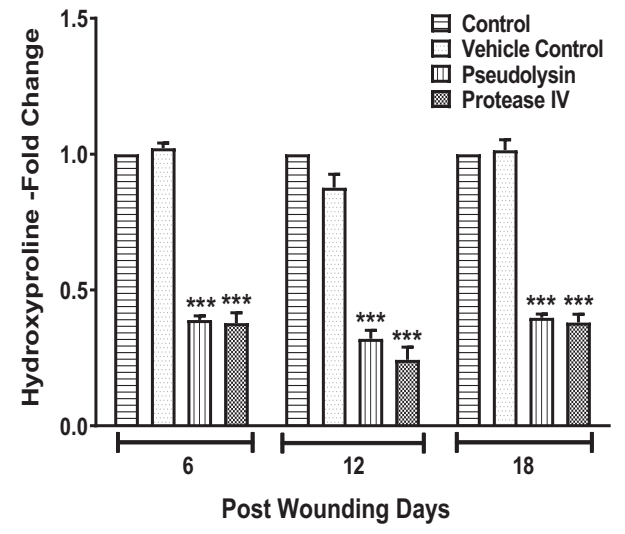

A
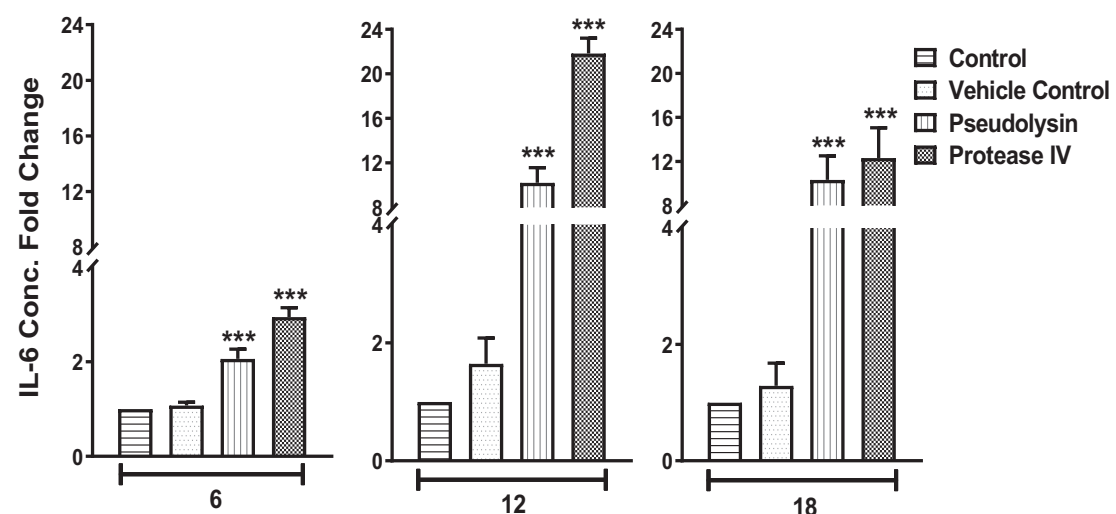

Post Wounding Days

C

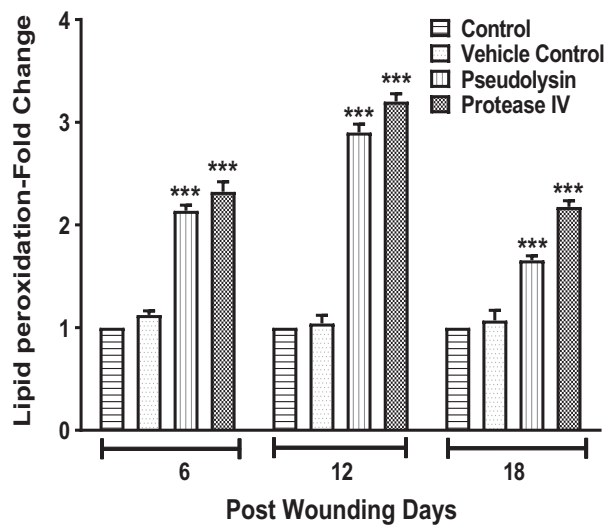

B levels as a sign of inflammation. Pseudolysin and protease IV treated animals showed increased IL-6 levels. The levels of inflammatory cytokine IL-6 were significantly higher in treated groups on 6th, 12th, and 18th day post wounding compared to control (Fig. 9c), on 6th day post wounding, there were 2-fold and 2.9-fold increase in the IL-6 levels in the pseudolysin and protease IV treated tissues, on 12th day there was 10-fold and 21-fold increase, and on 18th day 10fold and 12-fold increase was observed compared to both the control groups, indicating the prolonged and elevated inflammatory response during the wound-healing process.

Taken together, pseudolysin and protease IV mediated inhibition of wound-healing process was associated with (a) infiltration of leukocytes, (b) reduction in collagen accumulation, (c) decrease in microvessels, (d) increase in oxidative stress, and (e) prolonged and increase in IL-6 levels.

\section{Discussion}

Chronic wounds are a major problem associated with significant morbidity and mortality. The influence of microbial infection on delayed wound healing has remained as one of the 
production among others [23]. Emerging resistance to multiple classes of antibiotics by the $P$. aeruginos $a$ has been well established over the past few decades and periodical monitoring of susceptibility patterns will provide clinical outcome to various therapeutic approaches. In the present study, $46 \%$ of $P$. aeruginosa strains were showing a multidrug resistance pattern (MDR). MDR often attained through several mechanisms, such as acquiring targeted mutations, enhanced multidrug efflux systems, and production of modulatory enzymes [24]. P. aeruginosa can exist independently or co-habit along with other microbes to form microcommunities within a secreted matrix of extracellular polymeric substances in the form of biofilms. Biofilms protect bacteria against various types of stresses, including immune responses and antibiotics [25]. Biofilm formation plays an important role in bacterial pathogenesis [26]. $P$. aeruginosa strains tested in our study exhibited a significant correlation between antibiotic resistance and biofilm producing ability which was in agreement with earlier reports [1]. Biofilm formation is the major cause for the persistent infection, they communicate and respond within the biofilm by a process known as quorum sensing. Quorum sensing is a regulator of virulence and biofilm formation in P. aeruginosa. $P$. aeruginosa through quorum sensing orchestrate a symphony of virulence factors such as exoproteases, siderophores, exotoxins, and several secondary metabolites, which have been implicated in the pathogenesis [25]. Our results suggested that the bacterialconditioned medium of high biofilm producing strain of $P$. aeruginosa produced an array of secretory proteins. Furthermore, these secretory proteins showed cytotoxicity and inhibited cell migration on skin cells such as HDF and $\mathrm{HaCaT}$ cells in vitro as confirmed by MTT and wound scratch assay. Pseudomonas elastase isolated from the culture supernatant was found to be cytotoxic to A549 airway epithelial cells [27]. Collective cell migration is considered as a hall mark of wound repair [28]. In the present study, in vitro scratch assays showed that cells treated with bacterial proteins significantly reduced the rate of wound closure compared to control samples, although kinetics between the cell types varied. Moderate biofilm producing and low biofilm producing strains of $P$. aeruginosa were unable to show any type of such significant observations. This suggested presence or abundance of biomolecules in high biofilm producing strains responsible for virulence properties.

We further identified through mass spectroscopy that the high biofilm-forming strain of $P$. aeruginosa produced pseudolysin and protease IV abundantly in the bacterialconditioned medium. Earlier studies have also shown the production of secretory proteins elastase $\mathrm{B}$ and protease IV in the culture supernatants [9, 29-31]. However, our report is the first study to demonstrate the profiling of secretory proteins in a high biofilm-forming strain from diabetic wound isolate using LC/MS/MS analysis, which resulted in the identification of mature pseudolysin and protease IV proteins that elicited cytotoxicity. Pseudolysin and protease IV have been shown to play a major role in ocular infection, lung infection, disruption of epithelial tight junctions, and degradation of immunoglobulins, complement proteins, and fibrinogen [4].

We next attempted to investigate effects of pure pseudolysin and protease IV in ammonium sulfate fractions on cytotoxicity. Our analysis indicated that these fractions induced cytotoxic effects and inhibited migration even at lower concentrations.

Since both these proteins could not be purified separately, recombinant clones were prepared and cultured to produce individual proteins. This approach offered the possibility to analyze the individual effect of recombinant pseudolysin and protease IV. Several studies reported the synthesis of mature pseudolysin and mature protease IV by recombinant technology using E. coli and Pichia pastoris with functional characterization of the protease [32, 33]. Furthermore, to confirm the antiproliferative property of $P$. aeruginosa virulence proteins in vitro, recombinant pseudolysin and protease IV were tested for the proliferation potential on HDF, HaCaT cells and HUVECs using MTT assay. A dose-dependent significant decrease in cell viability was observed during the 48 -h treatment period. In the present study, a significant decrease in cell migration was observed on HDF, HaCaT cells and HUVECs. Cross talk between fibroblasts and keratinocytes resulting in coordinated proliferation and migration along with the angiogenesis is the vital component in the wound-healing process [34].

Pseudolysin is a $33-\mathrm{kDa}$ extracellular elastase (EC: 3.4.24.26) that belongs to the thermolysin (M4) like family of metallopeptidase and is the most abundant protease secreted by $P$. aeruginosa [32]. Pseudolysin is initially synthesized as $53.6 \mathrm{kDa}$ pre-proenzyme containing a signal peptide, a propeptide, and the C-terminal mature domain. Further cleavage by autoproteolysis in the periplasm results in the mature active protease of 33-kDa [35]. Earlier studies established pseudolysin as a major virulence factor of $P$. aeruginosa playing an important role in its pathogenesis [36]. Pseudolysin has the ability to cause lysis of elastin and some connective tissues and to destroy the blood vessels causing hemorrhage [37, 38].

Protease IV is a $26-\mathrm{kDa}$ Lysine-specific endoprotease (EC 3.4.21.50), initially synthesized as $48-\mathrm{kDa}$ pre-proenzyme containing three domains: signal sequence, propeptide domain, and mature protease. Intracellular cleavage results in the extracellular $26-\mathrm{kDa}$ mature active protease [8]. Earlier studies indicated protease IV as one of the major virulence factors of $P$. aeruginosa for its role in the 
pathogenicity of keratitis [39]. It is also known to degrade variety of host defense proteins such as fibrinogen, plasminogen, immunoglobulin $\mathrm{G}$ and the complement proteins $\mathrm{C} 1 \mathrm{q}$ and $\mathrm{C} 3$ [9].

Rodents are widely used to understand the dynamics of wound healing due to its low cost and ease of breeding and genetic modifications. Furthermore, the effect of recombinant pseudolysin and protease IV on cutaneous wound healing was evaluated in vivo by making excisional wounds in Swiss albino mice model. We used carbopol hydrogel as vehicle control to facilitate the retention of the proteins in the wound site. Hydrogel-mediated delivery of recombinant pseudolysin and recombinant protease IV represents potentially novel and effective means to study the wound healing progression. In rodents, wound contraction is the significant process in wound healing as their skin is mobile and contains thin sheets of striated muscles between the subcutaneous fat and the dermal layer [40]. Wounds treated with the two recombinant proteins took significantly longer time to heal when compared to that of both vehicle control and control in terms of wound closure and contraction.

The highly dynamic and orchestrated process of wound healing consists of different phases such as hemostasis, inflammation, proliferation, and remodeling [10]. Bacterial virulence factors may significantly delay the process of healing by prolonging inflammatory response, degrading extracellular proteins including collagen, inhibiting the cell proliferation and angiogenesis, and delaying reepithelialization [11]. Histological assessment of the skin is always considered as "gold standard" in diagnosing and demonstrating any degenerative and neoplastic conditions [18]. Ancillary techniques such as special stains (MT staining for collagen) and immunohistochemistry techniques along with the scoring system will help the accurate assessment of wound healing [27]. Histological scoring revealed reduced proliferation of fibroblast, keratinocytes, and endothelial cells resulting in reduced epithelialization in protein-treated groups of animals. Further image analysis of MT stained granulation tissues indicated a significant decrease in the collagen deposition in treatment groups compared to control. Findings of the present study on delayed epithelialization and collagen deposition upon treatment with bacterial secretory proteins were completely corroborated with the earlier published reports in LPS induced delayed wound model [41]. Recent studies demonstrated the action of pseudolysin in destroying human tissues by solubilizing elastin [37]. Taken together, the outcomes of the present investigation clearly establish the role of pseudolysin and protease IV in delaying wound healing by acting on extracellular matrix protein. In the present study, immunohistochemistry staining results revealed decreased proliferation of cells in treatment groups compared to vehicle control and control. A similar study that was performed earlier reported reduction in Ki67 expression indicating lower cellular proliferation in LPS induced delayed wound model [41]. Earlier results observed abnormal keratinocyte and fibroblast migration, proliferation and decreased vascularization in diabetic conditions leading to impaired wound healing [42]. Neovascularization or angiogenesis, the formation of new blood vessels from preexisting capillaries and their penetration toward wound site is an essential component of wound-healing process [43]. In the present study, using HUVEC cells significant cytotoxicity was elucidated and tube formation assay revealed the reduction in angiogenesis which was corroborated by immunohistochemistry staining results indicating the impaired angiogenesis. Collagen is abundantly present in the ECM and is involved in cell adhesion, cell migration, tissue repair, giving tensile strength to the tissue and plays a significant role in the maintenance of tissue homeostasis during the proliferation and remodeling phase of wound healing [44]. Hydroxyproline is an amino acid that plays a significant role in stabilizing the structural conformation of collagen, the principal protein in the ECM of skin. Since hydroxyproline is measured as a surrogate for total collagen and decreased concentration of hydroxyproline in granulation tissue indicates reduced amount of collagen which, in turn, may impair the wound-healing process [45]. Hydroxyproline content in the granulation tissue of pseudolysin and protease IV treated animals showed several fold decrease on days 6,12 , and 18 when compared to control samples.

Malondialdehyde has been widely used and considered as a biomarker for lipid peroxidation [46]. In this study, the tissue homogenates from the wound demonstrated the increase in the levels of MDA indicating increased levels of oxidative stress. Oxidative damage can reduce the cell survival rate, proliferation, differentiation, metabolism and induce apoptosis [47].

Collagen is formed in the skin by fibroblasts. High glucose condition induces oxidative stress and may lead to fibroblast dysfunction in diabetic patients and result in decreased collagen production [48]. The present study also confirmed the elevated levels of plasma IL-6 during the wound-healing process indicating the prolonged inflammation process. Cytokines such as IL-6 orchestrate the inflammatory process. Prolonged inflammation may play a critical role in delayed tissue regeneration. Based on the findings of the present study, we propose the action of virulence proteins, pseudolysin, and protease IV in delaying cutaneous wound healing through multiple mechanisms (Fig. 10).

In this study, we have identified two secretory proteins, pseudolysin and protease IV, that can significantly impact wound healing in both in vitro and in vivo models. These 


\section{Wound healing process}

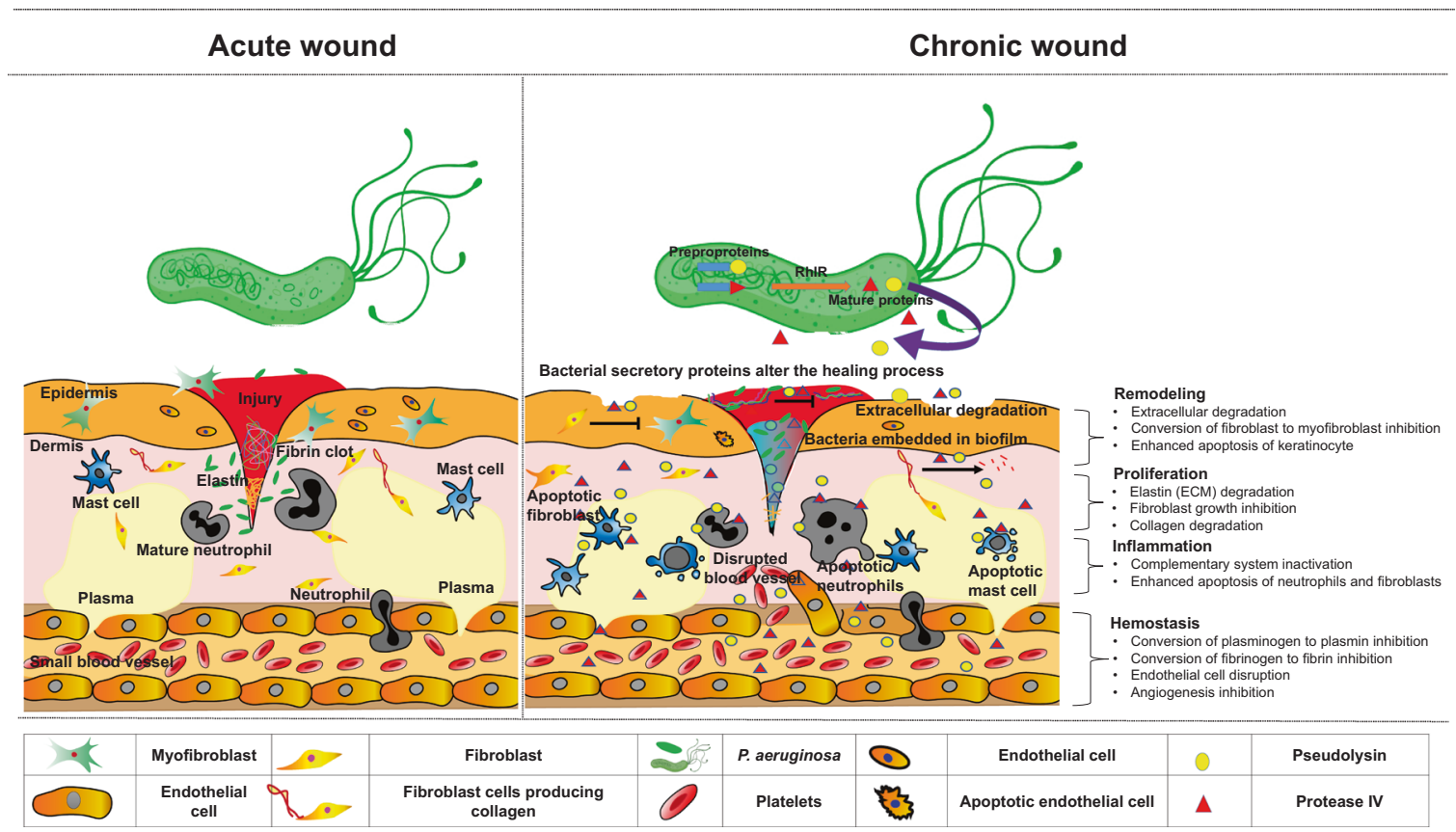

Fig. 10 Pseudolysin and protease IV of $P$. aeruginosa delayed cutaneous wound healing through multiple mechanisms. Normal wound healing involves a well-coordinated process involving multiple cell populations, the action of mediators like cytokines and growth factors, and also the extracellular matrix. The mature virulent proteins (pseudolysin and protease IV) produced by multidrug resistant and biofilm-forming $P$. aeruginosa cause apoptosis of neutrophils, macrophages, and mast cells leading to impaired

proteins induced cytotoxicity and reduced cell migration of cellular components of the wound. Furthermore, we observed both proteins reduced collagen accumulation, increased oxidative damage locally, and enhanced IL-6 levels systemically. We observed pseudolysin and protease IV significantly delayed wound healing and these proteins might serve as therapeutic targets for clinical management of wounds.

Acknowledgements We acknowledge TIFAC-CORE, Department of Science and Technology, Government of India, and Manipal Academy of Higher Education (MAHE), Manipal, India for infrastructure. Authors thank Dr. Raviraj Acharya, Kasturba Medical College, MAHE, Manipal, Dr. Shama Prasada K., Dr. T.G. Vasudevan, and Mr. Shreesha Bhat of Manipal School of Life Sciences, MAHE, Manipal, India for their help. KS thanks Indo-German Science and Technology Centre (2016-2019) for their support.

Funding Open access funding provided by Manipal Academy of Higher Education, Manipal.

\section{Compliance with ethical standards}

Conflict of interest The authors declare that they have no conflict of interest. phagocytosis. Prolonged inflammatory phase due to infection and elevated levels of pro-inflammatory cytokines inhibit the proliferation phase and remodeling phase of wound healing. Pseudolysin and protease IV enhance degradation of ECM, inhibit the proliferation of fibroblast, keratinocytes, and endothelial cells. They also cause inactivation of complement proteins and inhibit the conversion of plasminogen to plasmin and fibrinogen to fibrin leading to chronic wound healing.

Publisher's note Springer Nature remains neutral with regard to jurisdictional claims in published maps and institutional affiliations.

Open Access This article is licensed under a Creative Commons Attribution 4.0 International License, which permits use, sharing, adaptation, distribution and reproduction in any medium or format, as long as you give appropriate credit to the original author(s) and the source, provide a link to the Creative Commons license, and indicate if changes were made. The images or other third party material in this article are included in the article's Creative Commons license, unless indicated otherwise in a credit line to the material. If material is not included in the article's Creative Commons license and your intended use is not permitted by statutory regulation or exceeds the permitted use, you will need to obtain permission directly from the copyright holder. To view a copy of this license, visit http://creativecommons. org/licenses/by/4.0/.

\section{References}

1. Murali TS, Kavitha S, Spoorthi J, Bhat DV, Prasad ASB, Upton $\mathrm{Z}$, et al. Characteristics of microbial drug resistance and its correlates in chronic diabetic foot ulcer infections. J Med Microbiol. 2014;63:1377-85.

2. Maurice NM, Bedi B, Sadikot RT. Pseudomonas aeruginosa biofilms: host response and clinical implications in lung infections. Am J Respir Cell Mol Biol. 2018;58:428-39. 
3. Schmidtchen A, Holst E, Tapper H, Björck L. Elastase-producing Pseudomonas aeruginosa degrade plasma proteins and extracellular products of human skin and fibroblasts and inhibit fibroblast growth. Microb Pathog. 2003;34:47-55.

4. Kipnis E, Sawa T, Wiener-Kronish J. Targeting mechanisms of Pseudomonas aeruginosa pathogenesis. Med Mal Infect. 2006; 36:78-91.

5. Bainbridge T, Fick RB. Functional importance of cystic fibrosis immunoglobulin G fragments generated by Pseudomonas aeruginosa elastase. J Lab Clin Med. 1989;114:728-33.

6. Heck LW, Morihara K, McRae WB, Miller EJ. Specific cleavage of human type III and IV collagens by Pseudomonas aeruginosa elastase. Infect Immun. 1986;51:115-8.

7. Leduc D, Beaufort N, de Bentzmann S, Rousselle J-C, Namane A, Chignard M, et al. The Pseudomonas aeruginosa LasB metalloproteinase regulates the human urokinase-type plasminogen activator receptor through domain-specific endoproteolysis. Infect Immun. 2007;75:3848-58.

8. Traidej M, Marquart ME, Caballero AR, Thibodeaux BA, O'Callaghan RJ. Identification of the active site residues of Pseudomonas aeruginosa protease IV. Importance of enzyme activity in autoprocessing and activation. J Biol Chem. 2003;278:2549-53.

9. Engel LS, Hill JM, Caballero AR, Green LC, O'Callaghan RJ. Protease IV, a unique extracellular protease and virulence factor from Pseudomonas aeruginosa. J Biol Chem. 1998;273:16792-7.

10. Broughton G, Janis JE, Attinger CE. The basic science of wound healing. Plast Reconstr Surg. 2006;117:12-34.

11. Guo S, Dipietro LA. Factors affecting wound healing. J Dent Res. 2010;89:219-29.

12. Balakrishnan A, Guruprasad KP, Satyamoorthy K, Joshi MB. Interleukin-6 determines protein stabilization of DNA methyltransferases and alters DNA promoter methylation of genes associated with insulin signaling and angiogenesis. Lab Invest. 2018;98:1143-58.

13. Mathur T, Singhal S, Khan S, Upadhyay DJ, Fatma T, Rattan A. Detection of biofilm formation among the clinical isolates of staphylococci: an evaluation of three different screening methods. Indian J Med Microbiol. 2006;24:25-29.

14. Donelli G, Vuotto C, Cardines R, Mastrantonio P. Biofilm-growing intestinal anaerobic bacteria. FEMS Immunol Med Microbiol. 2012; 65:318-25.

15. Li JD, Feng W, Gallup M, Kim JH, Gum J, Kim Y, et al. Activation of NF-kappaB via a Src-dependent Ras-MAPK-pp90rsk pathway is required for Pseudomonas aeruginosa-induced mucin overproduction in epithelial cells. Proc Natl Acad Sci USA. 1998;95:5718-23.

16. Liang C-C, Park AY, Guan J-L. In vitro scratch assay: a convenient and inexpensive method for analysis of cell migration in vitro. Nat Protoc. 2007;2:329-33.

17. Bhat SK, Joshi MB, Ullah A, Masood R, Biligiri SG, Arni RK, et al. Serine proteinases from Bothrops snake venom activates PI3K/Akt mediated angiogenesis. Toxicon. 2016;124:63-72.

18. Prabhu V, Rao SBS, Rao NB, Aithal KB, Kumar P, Mahato KK. Development and evaluation of fiber optic probe-based helium-neon low-level laser therapy system for tissue regeneration-an in vivo experimental study. Photochem Photobiol. 2010;86:1364-72.

19. Fong Yen W, Basri M, Ahmad M, Ismail M. Formulation and evaluation of galantamine gel as drug reservoir in transdermal patch delivery system. Sci World J. 2015;2015:1-7.

20. Woessner JF. The determination of hydroxyproline in tissue and protein samples containing small proportions of this imino acid. Arch Biochem Biophys. 1961;93:440-7.

21. Williams H, Campbell L, Crompton RA, Singh G, McHugh BJ, Davidson DJ, et al. Microbial host interactions and impaired wound healing in mice and humans: defining a role for BD14 and NOD2. J Invest Dermatol. 2018;138:2264-74.
22. Trøstrup H, Lerche CJ, Christophersen LJ, Thomsen K, Jensen PØ, Hougen HP, et al. Chronic Pseudomonas aeruginosa biofilm infection impairs murine S100A8/A9 and neutrophil effector cytokines-implications for delayed wound closure? Pathog Dis. 2017;75:1-8.

23. Deep A, Chaudhary U, Gupta V. Quorum sensing and bacterial pathogenicity: from molecules to disease. J Lab Physicians. 2011;3:4-11.

24. Hirsch EB, Tam VH. Detection and treatment options for Klebsiella pneumoniae carbapenemases (KPCs): an emerging cause of multidrug-resistant infection. J Antimicrob Chemother. 2010;65:1119-25.

25. Hentzer M, Wu H, Andersen JB, Riedel K, Rasmussen TB, Bagge $\mathrm{N}$, et al. Attenuation of Pseudomonas aeruginosa virulence by quorum sensing inhibitors. EMBO J. 2003;22:3803-15.

26. Flemming H-C, Wingender J. The biofilm matrix. Nat Rev Microbiol. 2010;8:623-33.

27. Lee Y-H, Chang J-J, Chien C-T, Yang M-C, Chien H-F. Antioxidant sol-gel improves cutaneous wound healing in streptozotocin-induced diabetic rats. Exp Diabetes Res. 2012; 2012:504693.

28. Grada A, Otero-Vinas M, Prieto-Castrillo F, Obagi Z, Falanga V. Research techniques made simple: analysis of collective cell migration using the wound healing assay. J Invest Dermatol. 2017;137:11-16.

29. Twining SS, Kirschner SE, Mahnke LA, Frank DW. Effect of Pseudomonas aeruginosa elastase, alkaline protease, and exotoxin A on corneal proteinases and proteins. Invest Ophthalmol Vis Sci. 1993;34:2699-712.

30. Conibear TCR, Willcox MDP, Flanagan JL, Zhu H. Characterization of protease IV expression in Pseudomonas aeruginosa clinical isolates. J Med Microbiol. 2012;61:180-90.

31. Andrejko M, Zdybicka-Barabas A, Janczarek M, Cytryńska M. Three Pseudomonas aeruginosa strains with different protease profiles. Acta Biochim Pol. 2013;60:83-90.

32. Odunuga OO, Adekoya OA, Sylte I. High-level expression of pseudolysin, the extracellular elastase of Pseudomonas aeruginosa, in Escherichia coli and its purification. Protein Expr Purif. 2015;113:79-84.

33. Lin X, Xu W, Huang K, Mei X, Liang Z, Li Z, et al. Cloning, expression and characterization of recombinant elastase from Pseudomonas aeruginosa in Picha pastoris. Protein Expr Purif. 2009;63:69-74.

34. Shaw TJ, Martin P. Wound repair at a glance. J Cell Sci. 2009; 122:3209-13.

35. Kessler E, Ohman DE. Pseudolysin. In: Rawlings ND, Salvesen G, editors. Handbook of proteolytic enzymes. 3rd ed. San Diego, CA: Academic Press; 2013. p. 582-92.

36. Adekoya OA, Willassen N-P, Sylte I. Molecular insight into pseudolysin inhibition using the MM-PBSA and LIE methods. J Struct Biol. 2006;153:129-44.

37. Yang J, Zhao H-L, Ran L-Y, Li C-Y, Zhang X-Y, Su H-N, et al. Mechanistic insights into elastin degradation by pseudolysin, the major virulence factor of the opportunistic pathogen Pseudomonas aeruginosa. Sci Rep. 2015;5:9936.

38. Komori Y, Nonogaki T, Nikai T. Hemorrhagic activity and muscle damaging effect of Pseudomonas aeruginosa metalloproteinase (elastase). Toxicon. 2001;39:1327-32.

39. Engel LS, Hobden JA, Moreau JM, Callegan MC, Hill JM, O'Callaghan RJ. Pseudomonas deficient in protease IV has significantly reduced corneal virulence. Invest Ophthalmol Vis Sci. 1997;38:1535-42.

40. Davidson JM, Yu F, Opalenik SR. Splinting strategies to overcome confounding wound contraction in experimental animal models. Adv Wound Care. 2013;2:142-8. 
41. Crompton R, Williams H, Ansell D, Campbell L, Holden K, Cruickshank S, et al. Oestrogen promotes healing in a bacterial LPS model of delayed cutaneous wound repair. Lab Investig. 2016;96:439-49.

42. Xu F, Zhang C, Graves DT. Abnormal cell responses and role of TNF-in impaired diabetic wound healing. Biomed Res Int. 2013; 10:1-9.

43. Singer AJ, Clark RA. Cutaneous wound healing. N Engl J Med. 1999;341:738-46.

44. Kim Y, Ko H, Kwon IK, Shin K. Extracellular matrix revisited: roles in tissue engineering. Int Neurourol J. 2016;20:23-30.

45. Robin J. Methods for measuring hydroxyproline and estimating in vivo rates of collagen synthesis and degradation. In: Varga $\mathbf{J}$, Brenner DA, Phan SH, editors. Fibrosis research: methods in molecular medicine, vol. 117. New York, NY: Humana Press; 2005. p. 189-207.

46. Esterbauer H, Cheeseman KH. Determination of aldehydic lipid peroxidation products: malonaldehyde and 4-hydroxynonenal. Meth Enzymol. 1990;186:407-21.

47. Altavilla D, Saitta A, Cucinotta D, Galeano M, Deodato B, Colonna $\mathrm{M}$, et al. Inhibition of lipid peroxidation restores impaired vascular endothelial growth factor expression and stimulates wound healing and angiogenesis in the genetically diabetic mouse. Diabetes. 2001;50:667-74.

48. Buranasin P, Mizutani K, Iwasaki K, Pawaputanon Na Mahasarakham C, Kido D, Takeda K, et al. High glucoseinduced oxidative stress impairs proliferation and migration of human gingival fibroblasts. PLoS ONE. 2018;13:e0201855. 